\title{
COMPORTAMENTO HIDROSSEDIMENTOLÓGICO DE BACIA HIDROGRÁFICA COM RESERVATÓRIO
}

\author{
Paulo Rodrigo ZANIN ${ }^{1}$; Nadia Bernardi BONUMÁ ${ }^{2}$ Davide FRANCO ${ }^{3}$
}

\begin{abstract}
(1) Geógrafo e Mestre em Engenharia Ambiental pela Universidade Federal de Santa Catarina (UFSC). Campus Reitor João David Ferreira Lima/Bairro Trindade. Florianópolis (SC). Endereço eletrônico: paulorzgeo@gmail.com

(2) Dra ${ }^{a}$. Prof ${ }^{a}$ do Departamento de Engenharia Sanitária e Ambiental (ENS) da Universidade Federal de Santa Catarina (UFSC). Campus Reitor João David Ferreira Lima/Bairro Trindade. Florianópolis (SC). Endereço eletrônico: nadia.bonuma@ufsc.br

(3) Dr. Professor do Departamento de Engenharia Sanitária e Ambiental (ENS) da Universidade Federal de Santa Catarina (UFSC). Campus Reitor João David Ferreira Lima/Bairro Trindade. Florianópolis (SC). Endereço eletrônico: d.franco.ocean @gmail.com
\end{abstract}

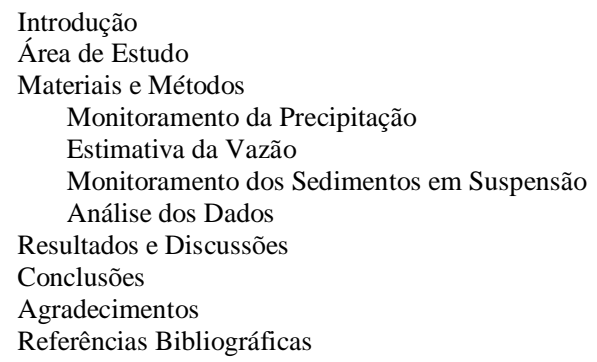

RESUMO - O represamento hídrico altera a hidrodinâmica do escoamento fluvial e dos processos de transporte e deposição de sedimentos. O presente trabalho tem por objetivo amostrar e analisar o comportamento de sedimentos suspensos em uma bacia hidrográfica de $5^{\text {a }}$ ordem fluvial, que possui um reservatório d'água em seu exutório. Foram realizadas 20 campanhas de amostragem de sedimentos em suspensão, de 2 a 3 metros a montante da barragem, em quatro profundidades da coluna d'água. Para amostrar a mistura água-sedimentos da descarga do reservatório foi utilizado um novo amostrador de sedimentos em suspensão, assim como um novo método de amostragem, dimensionalisados para esta represa. Os resultados do monitoramento mostraram que a concentração de sedimentos suspensos perto do fundo do reservatório é maior do que na superfície do mesmo, sendo que a amostragem do dia 05/09/14 indicou a ocorrência de correntes de turbidez de fundo. A análise estatística dos dados mostra que o sedimento em suspensão não responde rápidamente aos eventos de precipitação, havendo um retardo entre o pico da vazão e os valores máximos da descarga de sedimentos do reservatório. Com esta análise foram identificados dois processos hidrossedimentológicos reponsáveis pela descarga sólida desta represa. No entanto, somente um destes processos foi totalmente caracterizado, o qual é desencadeado pela chuva diária ocorrida entre o atraso temporal de 1 a 2 dias, gerando incremento de água e sedimentos na vazão com atraso de 1 dia, determinando parte da concentração de sedimentos na vazão do dia da amostragem. Já o outro processo, referente a vazão com atraso de 2 dias, que possui maior determinação nos sedimentos suspensos do dia da amostragem, ainda carece de uma maior amostragem espaço/temporal de precipitação e sedimentos suspensos para caracterização de sua gênese, podendo ser devido ao fenômeno de histerese.

Palavras-chave: Sedimentos em suspensão, Reservatório.

\begin{abstract}
Water damming altered the river hydrodynamics and the process of sediment transport and deposition. This study aims to sampling and analyze the behavior of suspended sediment in a watershed of river 5th order, which has a water reservoir in its river mouth. Were carried out 20 suspension sediment sampling, of 2 to 3 meters upstream from the dam, in four depths in the water column. To sample the mixture water-sediment of discharge from the reservoir a new sampler of suspended sediment was used, as well as a new sampling method, developed for this dam. The monitoring results showed that the concentration of suspended sediment near the bottom of the reservoir is greater than on the surface thereof, and the day of sampling 09/05/14 indicated the occurrence of bottom turbidity currents. Statistical analysis of the data shows that the suspension sediment does not quickly respond to precipitation events, there a delay between streampeak flow and the maximum values of the sediment discharge of reservoir. With this analysis were identified two hydrosedimentological processes responsible for the solid discharge of this dam. However, only one of these processes has been fully characterized, which is triggered by daily rainfall occurred between delay time of 1 to 2 days, generating increment of water and sediment in the streamflow with a delay of 1 day, determining of the concentration of sediment in streamflow of the day of sampling. Already the other process, referring to streamflow with delay of 2 days, which has greater determination in the day suspended sediment sampling, still lacks a larger space/time sample of precipitation and suspended sediments to characterize its genesis, may be due to the hysteresis phenomenon.
\end{abstract}

Keywords: Suspended sediment, Reservoir.

\section{INTRODUÇÃO}

Quando uma bacia hidrográfica é represada, o escoamento fluvial é alterado, afetando a dinâmica do transporte de sedimentos pelos rios (Brandt, 2000).

A montante da barragem, o remanso hidráulico afeta o nível de base dos rios afluentes, antecipando a deposição de material sedimentar de grande a média granulometria (seixos, grânulos e areia), e forçando a decantação dos sedimentos finos (silte e argila) ao longo do reservatório. Com a retenção dos sedimentos pelo represamento hídrico, o 
volume útil do reservatório é reduzido, sendo que o assoreamento pode chegar até as tomadas d'água, inviabilizando a exploração hídrica (Coiado, 2003; Infanti Jr. \& Fornasari Filho, 2003).

Ferreira (2010) ao analisar o assoreamento de reservatório com base em experimentos no canal hidráulico do Departamento de Engenharia Civil da Universidade de Aveiro, utilizando uma barragem com tomadas d'água e descarregador de fundo para simular um reservatório no canal hidráulico, constatou que a quantidade de sedimentos que transpõem a barragem é insignificante em relação à quantidade de sedimentos depositados no reservatório.

A deposição dos sedimentos no reservatório está condicionado pela circulação das águas do lago artificial, o qual geralmente é multidimensional e não uniforme, havendo circulações periódicas e permanentes. As diferentes densidades da água, em função da temperatura e turbidez, implicarão na estratificação das camadas d'água, favorecendo a formação de correntes dentro do reservatório (Yang \& Simões, 2006).

Uma corrente importante em termos hidrossedimentológicos é a corrente de turbidez, a qual se forma principalmente durante os períodos chuvosos, onde ocorre maior produção de sedimentos na bacia de contribuição e, conseqüentemente, maior descarga sólida afluente. Esta corrente caracteriza-se por um escoamento estratificado, devido à diferença de densidade causada pela alta concentração de sedimentos finos suspensos na descarga afluente, em relação à densidade da água do reservatório. Quando a descarga afluente rica em sedimentos chega ao reservatório, realizando primeiramente a deposição do material grosso transportado pelo leito, ocorre a imersão da descarga sólida em suspensão, gerando a estratificação desta camada d'água e propiciando a formação da corrente de turbidez. Na corrente de turbidez os sedimentos são transportados pela turbulência da água, podendo haver deposição, erosão, ressuspensão de sedimentos do fundo, e mistura desta camada com as águas do reservatório ao longo da corrente. Esta corrente pode ser caracterizada como não conservativa, à exceção de quando a erosão iguala a deposição, sendo capaz de espalhar sedimentos finos em toda a extensão do reservatório, podendo atingir a barragem e até transpor o barramento via descarregadores de fundo.

Além da descarga sólida afluente, as correntes de turbidez podem ser geradas por escorregamentos e deslizamentos de massa no contorno do reservatório, lançamento de resíduos de minérios, dragagem, assim como descargas de varrimento e de fundo de barragens (Alves, 2008; Santos Correia, 2012).

De acordo com a densidade da corrente de turbidez, ela pode ser classificada como de fundo, quando o escoamento afluente é mais denso que a água do reservatório, de superfície, quando o escoamento afluente é menos denso que a água do reservatório, e de intermediária, quando o escoamento afluente é mais denso do que a água de superfície e menos denso do que a água de profundidade do reservatório (Alves, 2008).

Já para jusante da represa, as alterações hidrossedimentológicas são outras. Devido à regulação da vazão e resultante redução de fluxo, o rio perde potência de escoamento (stream power) e, conseqüentemente, sua capacidade de transporte de sedimentos (Brandt, 2000). Além disso, o aporte de sedimentos de montante é significativamente reduzido pelo barramento hídrico, chegando a uma capacidade de retenção de 100\% em grandes barragens (Coiado, 2003), causando impactos geomorfológicos catastróficos nos ambientes fluviais de jusante e ambientes costeiros, como deltas e linhas de costa, pois com a redução do aporte de sedimentos, o rio aumenta sua capacidade de erosão (HudsonHedwards, 2007).

Assim sendo, o objetivo deste trabalho foi de amostrar e analisar o comportamento de sedimentos suspensos em uma bacia hidrográfica de $5^{\mathrm{a}}$ ordem fluvial, que possui um reservatório de água no seu exutório. Espera-se com esta análise caracterizar o comportamento sedimentológico e identificar os processos hidrossedimentológicos predominates no represamento hídrico desta bacia. Estes resultados irão auxiliar na compreensão sobre o transporte de sedimentos em bacias hidrográficas que tiveram seus rios principais represados, servindo de embasamento para estudos de engenharia e geologia, que visam 
quantificar o assoreamento e vida útil de reservatórios, como para estudos de geomorfologia fluvial, que visam caracterizar as mudanças nas formas fluviais e costeiras a jusante de represas, devido a redução do aporte sedimentar e aumento do poder de erosão fluvial.

\section{ÁREA DE ESTUDO}

A bacia hidrográfica da Represa Caunal, que é embutida na bacia hidrográfica do Rio Preto ( $6^{\mathrm{a}}$ ordem fluvial), se situa no planalto Norte Catarinense, mais precisamente no município de Rio Negrinho. A represa Caunal, Figura 1, volta-se a regular as vazões para a PCH Salto Grande, localizada a jusante, ambas de propriedade da Companhia Volta Grande de
Papel - CVG. A bacia hidrográfica da represa Caunal possui uma área de $199,32 \mathrm{~km}^{2}$ com uma densidade de drenagem de $1,96 \mathrm{~km} / \mathrm{km}^{2}$, constituindo uma bacia de $5^{\mathrm{a}}$ ordem fluvial, com amplitude altimétrica de 237 metros e tempo de concentração de 9,36h.

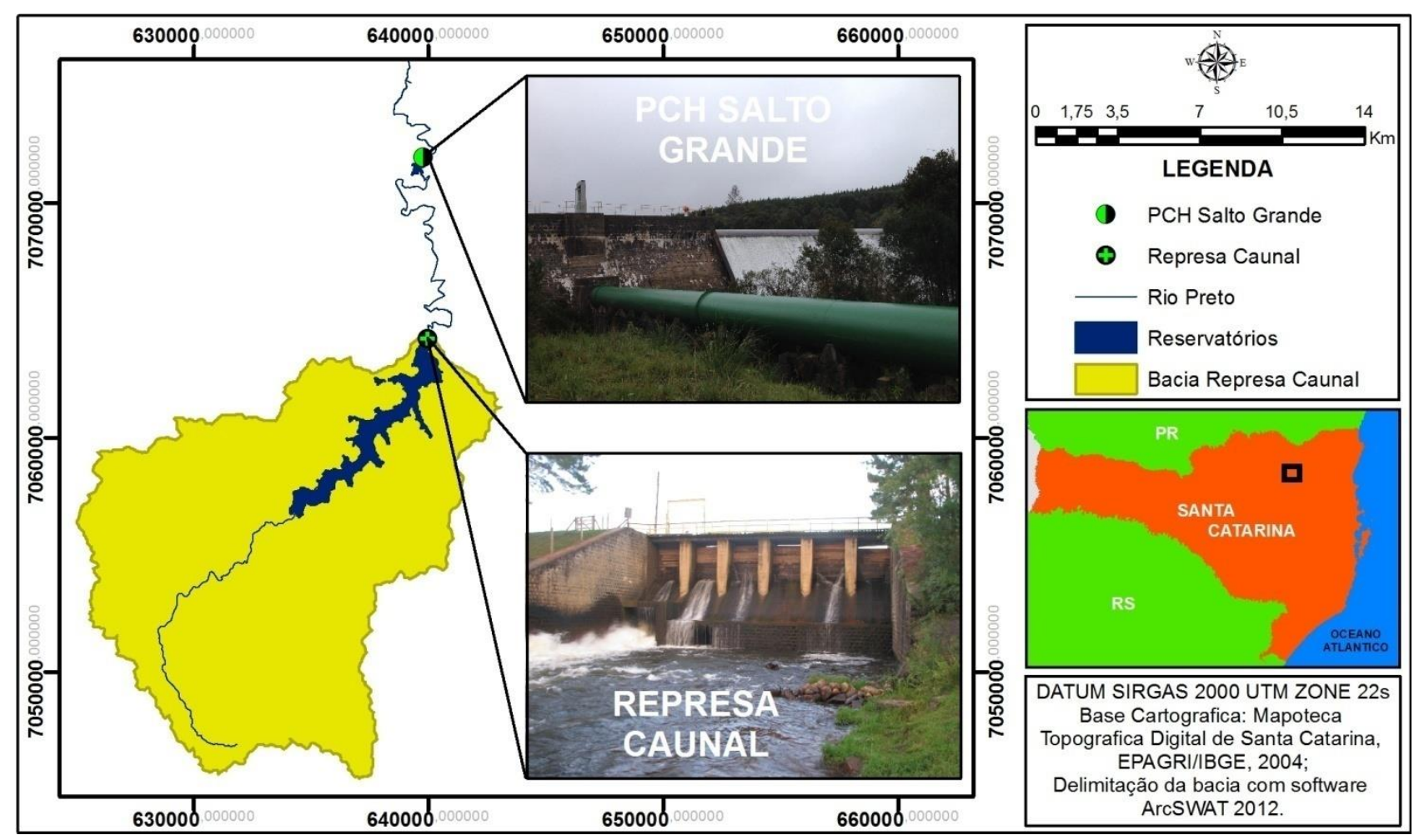

Figura 1. Localização da área de estudo.

A represa Caunal foi construída em 1957, e reconstruída em 1985 devido ao rompimento da represa antiga em 1983. Esta represa constitui-se de uma barragem de enrocamento com vertedouro de soleira livre de concreto, Figuras 2 a 4, com altura da soleira de escoamento em 4,90m, havendo um coroamento acima do vertedouro com $7,5 \mathrm{~m}$ de altura e 18,10 metros de largura, sendo o espaço entre o vertedouro e o coroamento fechado com madeira para aumentar o nível da represa acima da base do vertedouro. Também existem dois descarregadores de fundo de formato quadrangular, um de $1 \times 1 \mathrm{~m}$, o qual fica sempre fechado, e outro de $2 \times 2 \mathrm{~m}$ que é operado diariamente através de uma comporta, para manter $\mathrm{o}$ armazenamento $\mathrm{e}$ fornecimento hídrico conforme a demanda da $\mathrm{PCH}$ de jusante. Para situações de emergência (máximas pluviométricas) o vertedor é aberto e existem dois canais extravasores, um na ombreira direita e outro na ombreira esquerda da barragem.

$\mathrm{O}$ reservatório gerado pela represa Caunal, Figura 5, possui um volume de 4,63 x $10^{7} \mathrm{~m}^{3}$ ocupando uma área de $8,977 \mathrm{~km}^{2}$ para seu nível máximo de operação. 


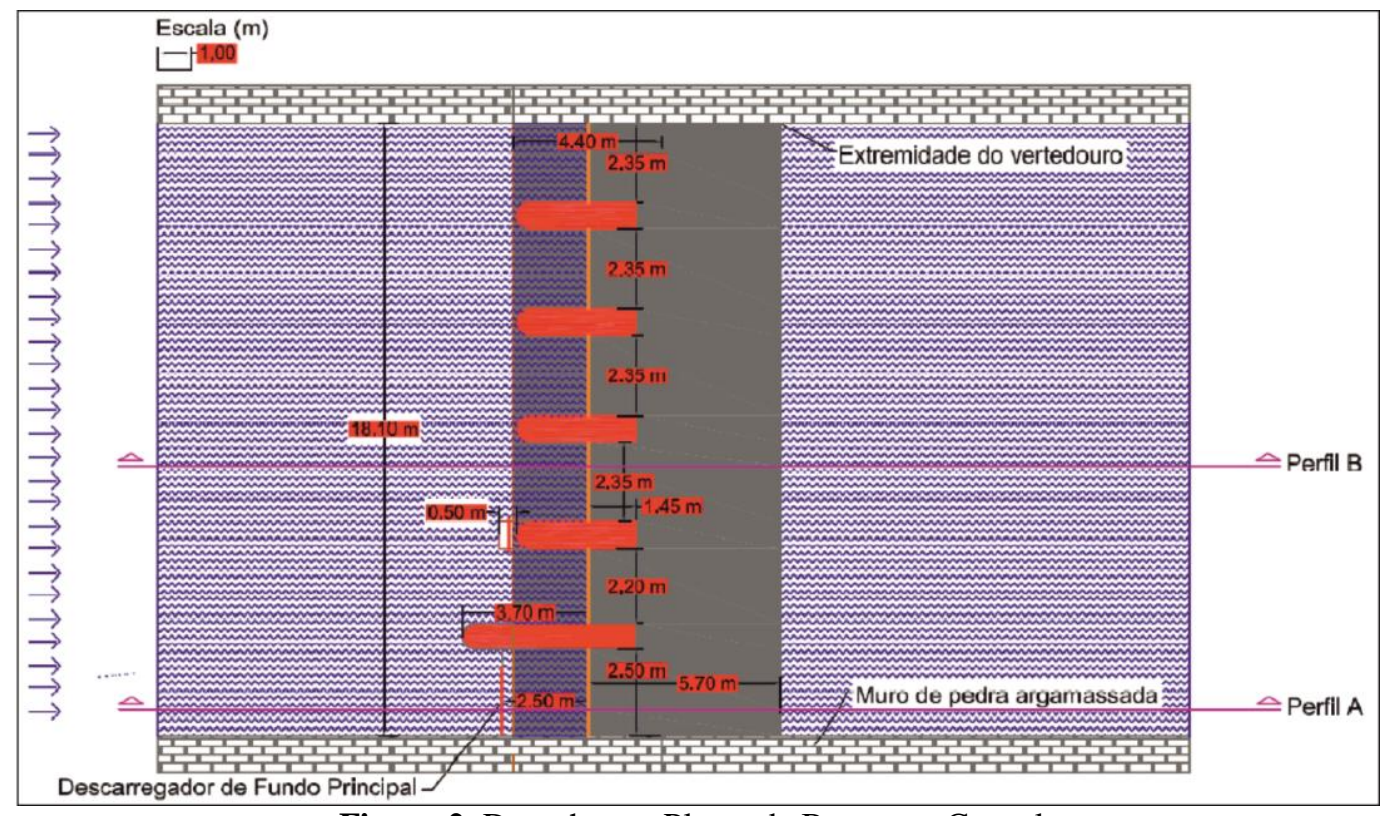

Figura 2. Desenho em Planta da Barragem Caunal.

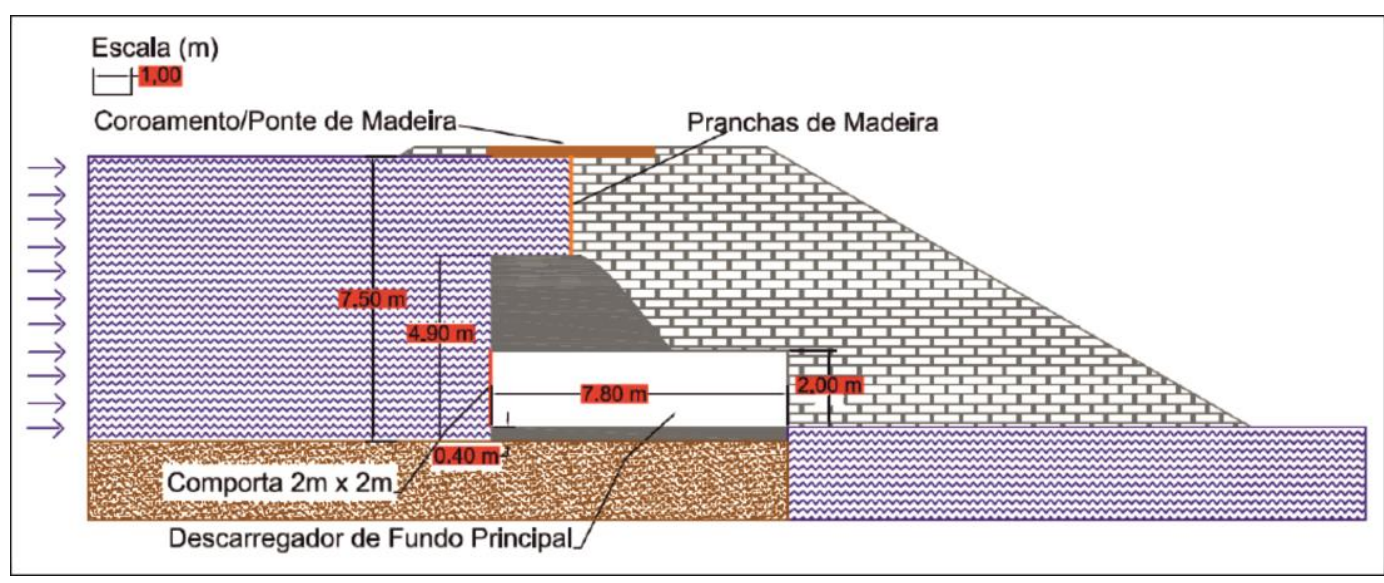

Figura 3. Perfil A. Barragem Caunal.

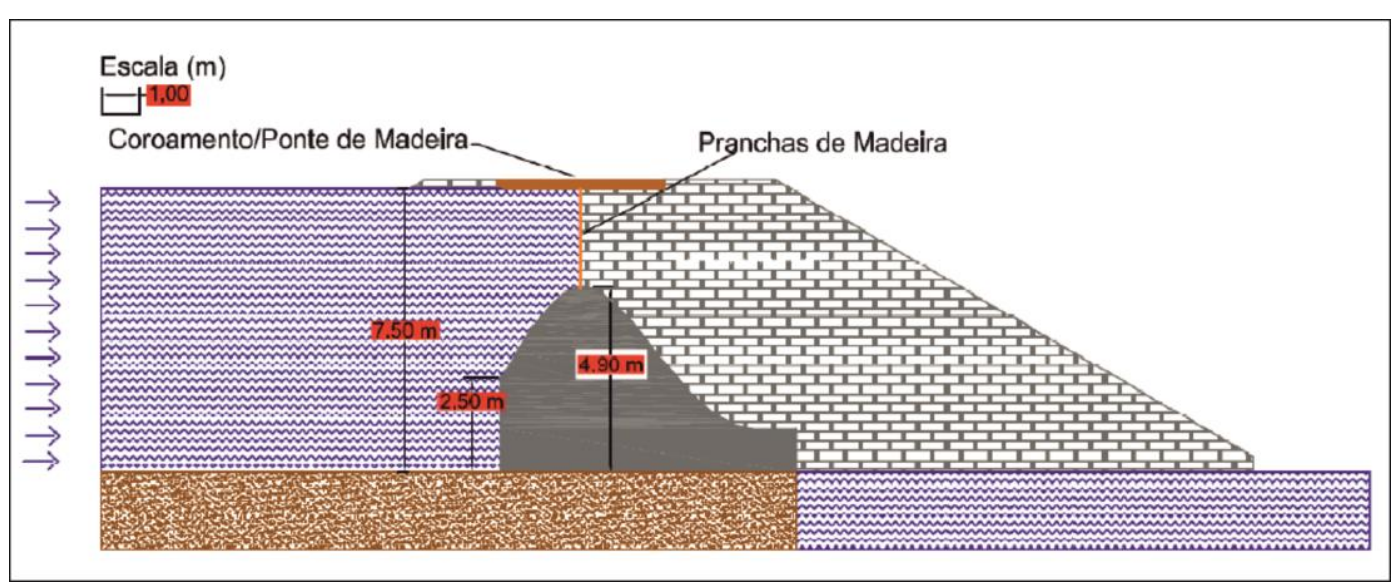

Figura 4. Perfil B. Barragem Caunal. 


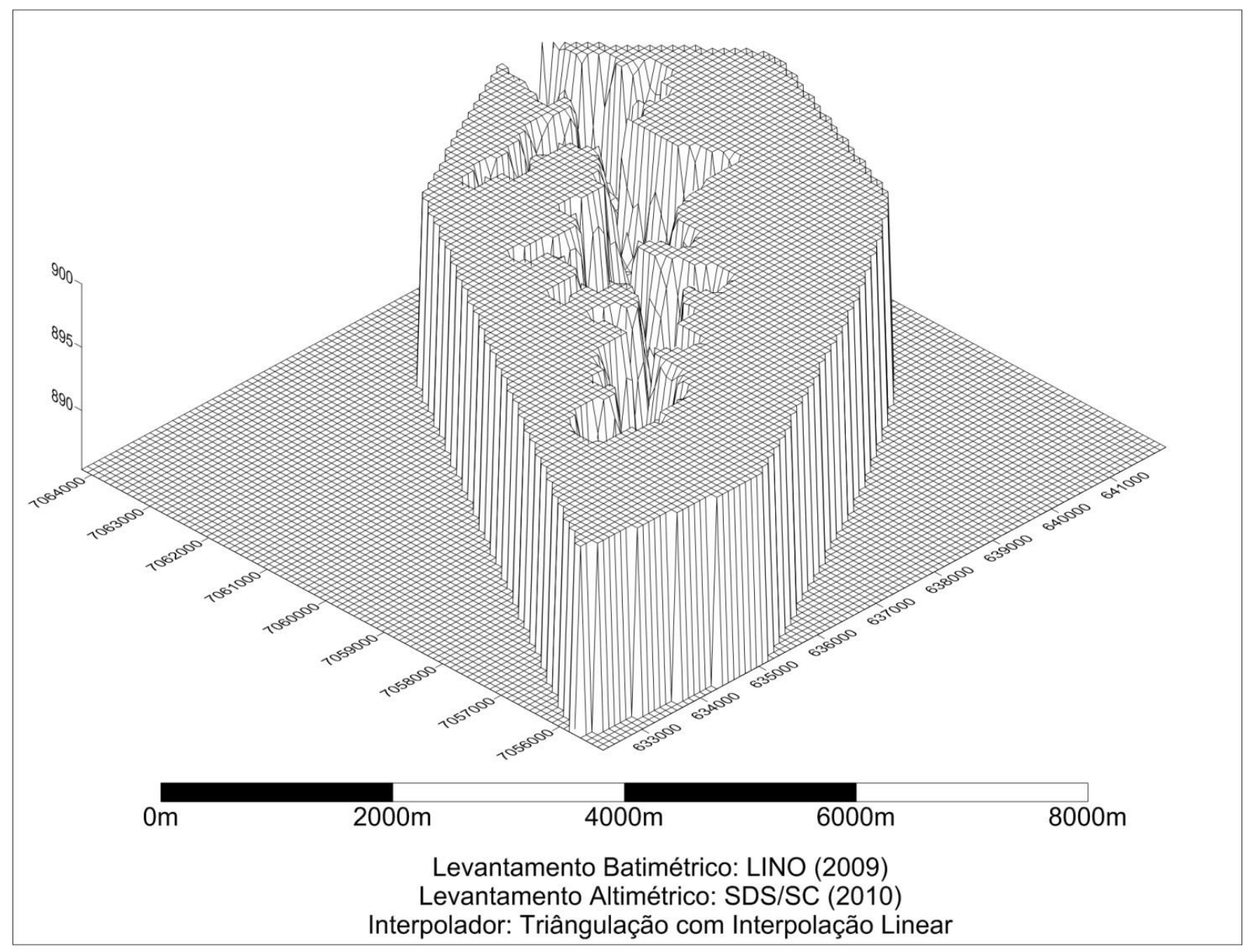

Figura 5. Reservatório da Barragem Caunal.

\section{MATERIAIS E MÉTODOS}

\section{Monitoramento da Precipitação}

Para monitorar a precipitação da área de estudo foram utilizados dados do pluviógrafo de uma estação meteorológica Davis, localizada nas proximidades da $\mathrm{PCH}$ Salto Grande, $7 \mathrm{~km}$ a jusante da bacia de contribuição da represa Caunal.

\section{Estimativa da Vazão}

Para calcular a vazão dos descarregadores de fundo da represa, com base no registro de cotas do reservatório, abertura da comporta da barragem, e geometria do orifício de descarga, foi utilizada a equação 1 (Porto, 2003).

$$
q=C_{d} a \sqrt{2 g h_{1}} \text { para } h_{1} \geq 0,81 h_{3}\left(\frac{h_{3}}{a}\right)^{0,72}
$$

Equação 1 d'água a montante $(\mathrm{m}) ; h_{3}$ o nível d'água a jusante $(\mathrm{m})$.

O coeficiente de descarga para uma comporta vertical, considerando uma distribuição de pressão hidrostática, depende da abertura relativa $\left(\mathrm{h}_{1} \cdot \mathrm{a}^{-1}\right)$ e do grau de submersão do escoamento a jusante $\left(h_{3} \cdot a^{-1}\right)$. Para descarga livre o coeficiente foi calculado usando a equação 2 (Swamee, 1957 apud Porto, 2003).

$$
C_{d}=0,611\left(\frac{h_{1}-a}{h_{1}+15 a}\right)^{0,072}
$$

Equação 2

Para corrigir a supressão de contração da veia nos descarregadores de fundo da represa, foi usada a equação 3 (Porto, 2003).

$$
C_{d}^{\prime}=C_{d}(1+0,15 k)
$$

Equação 3

Sendo $C_{d}^{\prime}$ o coeficiente de descarga corrigido para orifícios retangulares; e o $\left(m^{3} \cdot s^{-1} \cdot m^{-1}\right) ; C_{d}$ o coeficiente de descarga; $a$ a altura de abertura do orifício (m); $h_{1}$ o nível 
coeficiente $k$ é a relação entre o perímetro do orifício onde ocorre a supressão da contração do jato e o perímetro total do oríficio, definido pela equação 4 .

$$
k=\frac{2 a+b}{2(a+b)}
$$

Equação 4

Sendo $a$, a altura do orifício (m) e $b$ a largura do mesmo (m). Para calcular a descarga líquida do vertedouro de soleira livre foi usada a equação 5 para o perfil Creager, e a equação 6 para o perfil retangular de parede espessa (Porto, 2003), considerando a largura efetiva, devido ao vertedouro da represa Caunal possuir 5 pilares, constituindo 6 vãos, sendo 4 com perfil Creager e $1 \mathrm{com}$ perfil retangular de parede espessa.

$$
Q=2,215\left(\frac{h}{h_{d}}\right)^{0,148}\left[L-2\left(n k+k_{a}\right) h_{d}\right] h_{d}^{3 / 2}
$$

Equação 5

Sendo $Q$ a vazão $\left(m^{3} \cdot s^{-1}\right) ; L$ a largura livre do vertedouro $(\mathrm{m}) ; h$ a carga hidráulica efetiva (m); $h_{d}$ a carga hidráulica sobre a crista do vertedor $(\mathrm{m}) ; n$ o numero de pilares; $k$ o coeficiente de contração dos pilares $=0,04$ (Sinniger \& Hager, 1989); e $k_{a}$ o coeficiente de contração das ombreiras $=0,00$ (Sinniger \& Hager, 1989).

$$
Q=C_{d v p e} 1,704\left[L-\left(n k+k_{a}\right) h_{d}\right] h_{d}{ }^{3 / 2}
$$

Equação 6

Sendo $C_{d v p e}$ o coeficiente de descarga para vertedor de parede espessa (valor de 0,858 - adaptado de King, 1954 segundo Porto, 2003).

Para os dois canais extravasores da represa, os quais em terra só auxiliam no extravasamento do excesso de vazão de eventos de máximas pluviométricas, considerou-se seu equacionamento de vazão pela fórmula de canais retangulares, com a velocidade calculada pela método de Manning (PORTO, 2003), equação 7.

$$
Q=A\left(\frac{1}{n} R_{h^{\frac{2}{3}}} I_{o^{\frac{1}{2}}}\right)
$$

Equação 7

Sendo $A$ a área $\left(\mathrm{m}^{2}\right) ; R_{h}$ o raio hidráulico $(\mathrm{m}) ; I_{o}$ a declividade média do canal $\left(\mathrm{m} . \mathrm{m}^{-1}\right)$; e $n$ o coeficiente de rugosidade de Manning, definido para canais de terra, retilíneos e uniformes em condições regulares $(0,023)$.

Devido a um vazamento nas pranchas de madeira (+/- $20 \mathrm{~cm}$ de altura cada), que selam o vertedouro da represa Caunal durante sua operação normal, após o evento de máxima ocorrido em 06/2014, devido a retirada e recolocação destas pranchas que ocasionou a quebra parcial de uma delas, este vazamento foi calculado com a equação 1, considerando a abertura de metade da altura da prancha com vazamento. Vale salientar que existem outros vazamentos em outras pranchas, sendo estimado somente o mais expressivo.

\section{Monitoramento de Sedimentos em Suspensão}

Apesar de a forma tradicional de amostragem da descarga sólida de reservatórios ser por meio de um posto hidrossedimentométrico localizado logo a jusante da barragem, nesta pesquisa optou-se pelo monitoramento logo a montante da estrutura hidráulica, pois o canal de jusante não constitui uma seção ideal para fluviometria, e também por que além do cálculo da descarga sólida, este estudo buscou analisar a estratificação de sedimentos suspensos na coluna d'água do reservatório.

A quantificação de sedimentos que transpõem a barragem foi realizada pelo método indireto da amostragem da mistura água-sedimentos, com posterior cálculo da Concentração de Sedimentos em SuspensãoCSS (Carvalho, 2008). As amostragens foram realizadas de 2 a 3 metros a montante da barragem Caunal, na margem onde se localizam os descarregadores de fundo. A definição desta distância foi baseada no fato de não haver curvatura da lâmina d'água do reservatório ao se aproximar do vertedor, devido a este estar fechado com pranchas de madeira, sendo aberto somente em eventos de máximas pluviométricas, e também para evitar a sucção do amostrador pelo orifício.

$\mathrm{O}$ método de amostragem utilizado foi adaptado do método para canais fluviais naturais, através de Amostragem por Integração Pontual (Carvalho, 2008). Em relação aos locais das amostragens pontuais, foi criado um 
método para amostrar a CSS na descarga da barragem Caunal. Este método foi inspirado no método de B.C. Colby (segundo Carvalho, 2008), o qual, voltado para canais fluviais recomenda dividir a coluna d'água na vertical em 5 frações iguais, realizando as medições nos centros destas frações, sendo que todas as amostras devem ser adquiridas com mesmo tempo de amostragem, devendo ser levada em conta a velocidade da corrente para cada fração da coluna d'água (Carvalho, 2008). Como se trata de uma represa com a descarga sólida ocorrendo predominantemente por um descarregador de fundo, ao invés de um canal fluvial com maior velocidade ocorrendo ao centro do escoamento hídrico, a coluna d'água foi divida em três frações iguais $(1 / 3,2 / 3,3 / 3)$ sendo a amostragem realizada ao meio das frações, mais uma amostragem na base do reservatório, coletando a mistura de água e sedimentos a $25 \mathrm{~cm}$ do fundo, devido a vazão ocorrer predominantemente na parte inferior da barragem. O intuito destas divisões da coluna d'água é analisar a extratificação da concentração de sedimentos suspensos, sendo que para o cálculo da descarga sólida, foram consideradas somente as medições pontuais nos locais onde estava ocorrendo vazão efluente.

Para amostrar a mistura água-sedimentos na represa foi construído um amostrador de sedimentos em suspensão, denominado de $\mathrm{ZN}$ 2014, o qual, inspirado nos amostradores da série norte americana DH-48 e P-61, foi dimensionado para esta represa, Figura 6.

O amostrador $\mathrm{ZN}-2014$, possui bico com diâmetro de $1 \mathrm{~cm}$, com um recipiente de 1 litro sob uma inclinação de $20^{\circ}$, para facilitar a saída de ar do recipiente de coleta, e um sistema simples de abertura do recipiente (uma rolha associada a uma corda), para amostragens pontuais nas diferentes camadas d'água. Como o equipamento não possui sistema de fechamento, ele ficou estácionário em cada ponto de amostragem por no mínimo 5 minutos, para garantir o enchimento total do recipiente (tempo medido em laboratório foi de aprox. 3 minutos, sendo verificado em campo pela emersão de bolhas de ar), para evitar a alteração da amostra nas camadas d'água superiores durante a retirada do equipamento (Vale salientar que após o enchimento total do recipiente não ocorre recirculação d'água no mesmo, pois só existe um pequeno orifício na garrafa). $\mathrm{O}$ amostrador também possui um leme na parte traseira para mater o bico na direção do fluxo hídrico, e um cabo de 9 metros desmontável.

Como o bico do referido amostrador não fica posicionado totalmente na horizontal, como ocorre nos equipamentos da série norte americana, foi verificada a validade das coletas do ZN-2014 com base em duas amostragens na camada superfícial em paralelo com o amostrador DH-48, sendo comparadas posteriormente, obtendo uma diferença média de 2,27\% nos valores de CSS, a qual é aceita pelo método 2540D do Standard Methods $20^{\text {th }}$ Edition (Clesceri, et al.,1998), como diferença entre uma amostra e sua réplica (Diferença de até 5\%).

Após coletar as amostras da mistura água-sedimento, estas foram analisadas em laboratório (Laboratório Integrado de Meio Ambiente - LIMA/ENS/UFSC), através da técnica de filtragem, de acordo com o método 2540D do Standard Methods $20^{\text {th }}$ Edition (CLESCERI, et al. 1998) para obter a Concentração de Sedimentos em Suspensão CSS.

Depois de obter a CSS, foi calculada a descarga sólida. Como a vazão ocorre por orifícios ou vertedores e a amostragem de CSS é realizada em pontos ao centro ou próximos destes orifícios/vertedores, optou-se por uma adaptação da fórmula apresentada por Carvalho (2008) para os métodos de igual incremento de largura ou igual incremento de descarga para rios. Ao invés de usar o valor médio da CSS multiplicado pelo valor total de vazão e por um fator de correção de unidades, foi utilizado a CSS pontual multiplicada pela respectiva vazão no ponto de amostragem e pelo fator de correção de unidades, e posteriormente foram somadas as descargas sólidas dos diferentes orifícios/vertedores em operação, conforme equação 8.

$$
Q_{s s t}=\sum_{i}^{n} 0,0864 Q_{i} C_{i}
$$

Equação 8

Sendo $Q_{\text {sst }}$ a descarga sólida em suspensão total (ton. dia ${ }^{-1}$ ); $Q_{i}$ a vazão no ponto de amostragem de $C_{i}\left(m^{3} . s^{-1}\right)$; e $C_{i}$ a medida pontual de CSS no local da $Q_{i}$ $\left(m g \cdot l^{-1}\right)$. 


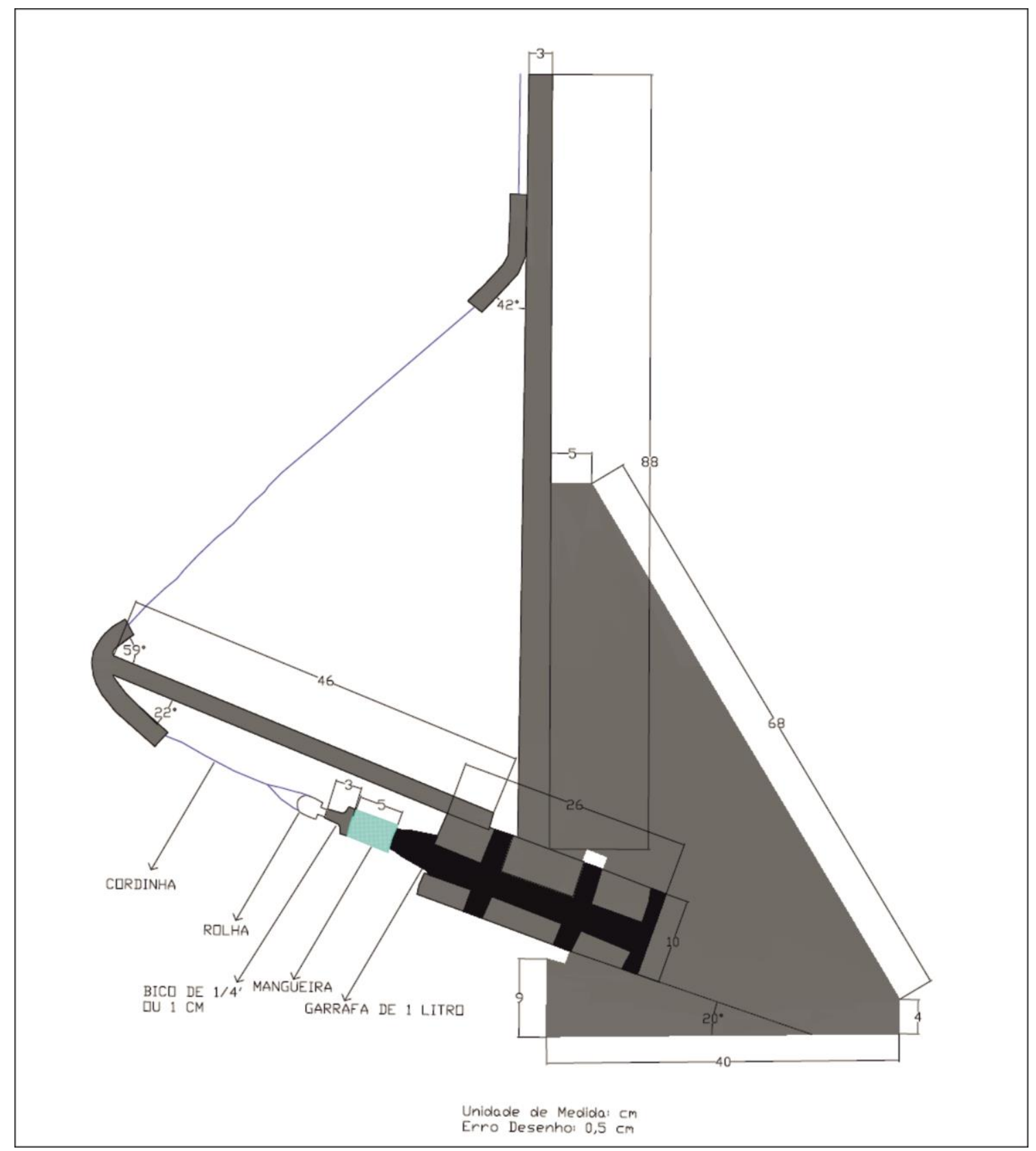

Figura 6. Diagrama esquemático do amostrador ZN-2014.

\section{Análise dos Dados}

Para analisar os dados medidos e estimados, foram utilizados gráficos, assim como técnicas estatísticas univariadas (média ponderada, mediana, $1^{\circ}$ e $3^{\circ}$ quartis), e técnicas estatísticas multivariadas (correlação e regressão).

Além dos dados de CSS de fundo, vazão instantânea e chuva acumulada em $24 \mathrm{~h}$, foram realizados atrasos (Lags) na vazão e chuva acumulada em $24 \mathrm{~h}$ em até 4 dias, com o intuito de verificar possíveis retardos nas repostas da descarga da represa.
Com intuito principal de realizar uma análise exploratória, foram utilizadas as correlações de Kendall Tau e Spearman Rank (segundo Wilks, 2006), sendo consideradas válidas as correlações com significância de $10 \%$.

Posteriormente, para as variáveis com correlação significante nas correlações nãoparamétricas, foram verificadas a existência ou não da normalidade na distribuição de frequência destas variáveis, atravéz do teste de Shapiro-Wilk (segundo Wilks, 2006), considerando uma significância de 5\% para 
definição das variáveis não gaussianas. Para estas variáveis, a melhor transformação foi adotada atravéz do valor de lambda do método Box-Cox (segundo Wilks, 2006). Como o cálculo de lambda não aceita o valor zero, foi somado uma constante nas variáveis com necessidade de transformação. $O$ valor desta constante foi definido em função do menor valor da série de dados destas variáveis, com exceção do zero, resultando no valor de 0,10 .

Com variáveis normais, ou normalizadas (transformadas), foi calculada a correlação de Pearson-r (segundo Wilks, 2006), considerando uma significância de $1 \%$.

Por fim, utilizando as variáveis que obtiveram correlação linear significante com a CSS, foi construído um modelo de regressão linear multivariado (segundo Wilks, 2006).

Para construir este modelo, primeiramente foram calculados os valores de F-Fisher para adicionar e remover variáveis de acordo com significância de $10 \%$ e $5 \%$ respectivamente. Posteriormente, os coeficientes de regressão foram validados pelo teste de t-student, para significância de 5\%, e pela ANOVA, para significância de 1\%. Para validar os resultados do modelo foram utilizados o coeficiente de determinação ajustado pelos graus de liberdade $\left(R^{2} p\right)$, erro padrão da estimativa, assim como a analise dos resíduos, verificando a necessidade de distribuição normal da frequência dos mesmos, e ausência de relação linear com as variáveis preditoras.

Além disso também foi calculada a autocorrelação parcial para os dados de vazão, com seu respectivo erro padrão multiplicado por dois, segundo definição de Wei (2006). Como esta correlação serial não aceita dados perdidos (Missing Data) na realização do cálculo, foram corrigidos os dados faltantes de nível, usando a média do dia anterior e do dia posterior, e para os dados de abertura de comporta foram usados os dados do dia anterior ao dado faltante, pois segundo o operador da barragem, os dados faltantes se referem aos dias em que o operador não visitou a represa, e desta forma sem modificações na operação.

\section{RESULTADOS E DISCUSSÃO}

Esta pesquisa totalizou 20 campanhas de amostragem da CSS na represa Caunal. Os dados pontuais com suas respectivas vazões, dados de operação da represa, e a descarga sólida total de cada campanha estão descritos na Tabela 1. Nesta Tabela observa-se que as amostragens contemplaram níveis do reservatório entre $5,8 \mathrm{~m}$ e 7,5m com abertura da comporta principal entre $0 \mathrm{~cm}$ e $200 \mathrm{~cm}$. Em relação à distribuição da CSS ao longo da coluna d'água, constata-se que nas operações a, c e d (descritas mais adiante) a maior CSS se situa ao fundo da represa, podendo ser devido à decantação dos sedimentos suspensos ao longo do reservatório. Já na operação $b$, no qual o vertedor é aberto, os sedimentos suspensos são mais expressivos nas camadas superiores da coluna d'água, em consequiência da maior vazão nestas camadas durante este tipo de operação.

Ao longo das 20 campanhas foram amostrados sedimentos suspensos em quatro formas de operação da descarga líquida da represa, sendo elas:
A) Descarga pelo descarregador de fundo principal (35\% das amostragens);

B) Descarga pelos dois descarregadores de fundo, vertedouro e canais extravasores $(5 \%$ das amostragens);

C) Descarga somente pelo vazamento em uma das pranchas do vertedor $(30 \%$ das amostragens);

D) Descarga pelo descarregador de fundo e vazamento em uma das pranchas do vertedor (30\% das amostragens).

A porcentagem de ocorrência de cada operação no recorte temporal de registros da represa (2010 a 2014), no ano de monitoramento (2014), assim como a proporção de amostragem em cada operação, pode ser visualizado na Tabela 2 , onde se constata que as descargas líquidas da represa pelo descarregador de fundo são predominantes ao longo do período de monitoramento e conjunto amostral de CSS. 
Tabela 1. Síntese dos dados amostrais.

\begin{tabular}{|c|c|c|c|c|c|c|c|c|c|c|}
\hline \multirow{2}{*}{ Data } & \multicolumn{2}{|c|}{ Amostra } & \multirow{2}{*}{$\begin{array}{l}\text { Nível } \\
(\mathrm{m})\end{array}$} & \multirow{2}{*}{$\begin{array}{c}\text { Abertura } \\
\text { C.G. }(\mathrm{cm})^{* * *}\end{array}$} & \multirow{2}{*}{$\begin{array}{c}\text { CSS } \\
\left(\mathrm{mg} \cdot 1^{-1}\right)\end{array}$} & \multirow{2}{*}{$\begin{array}{l}\text { Média P. } \\
(\mathrm{CSS})^{* * * *}\end{array}$} & \multirow{2}{*}{$\begin{array}{c}\text { Perfil } \\
\text { CSS***** }\end{array}$} & \multirow{2}{*}{$\begin{array}{c}\mathrm{Q} \\
\left(\mathrm{m}^{3} \cdot \mathrm{s}^{-1}\right)\end{array}$} & \multirow{2}{*}{ Operação } & \multirow{2}{*}{$\begin{array}{c}\text { DS } \\
\left(\text { t.dia }^{-1}\right)\end{array}$} \\
\hline & Posição & $\mathrm{h}(\mathrm{m})$ & & & & & & & & \\
\hline \multirow{4}{*}{$27 / 02 / 14$} & Fundo* & 6,55 & \multirow{4}{*}{6,80} & \multirow{4}{*}{15} & 11,67 & \multirow{4}{*}{10,35} & 1,13 & 2,06 & \multirow{4}{*}{ a } & \multirow{4}{*}{2,08} \\
\hline & 3/3.h & 5,67 & & & 10,33 & & 1,00 & 0,00 & & \\
\hline & 2/3.h & 3,40 & & & 9,09 & & 0,88 & 0,00 & & \\
\hline & 1/3.h & 1,13 & & & 6,67 & & 0,64 & 0,00 & & \\
\hline \multirow{4}{*}{$12 / 03 / 14$} & Fundo* & 5,79 & \multirow{4}{*}{6,04} & \multirow{4}{*}{2} & 9,75 & \multirow{4}{*}{7,43} & 1,31 & 0,28 & \multirow{4}{*}{ a } & \multirow{4}{*}{0,23} \\
\hline & 3/3.h & 5,03 & & & 6,50 & & 0,88 & 0,00 & & \\
\hline & 2/3.h & 3,02 & & & 5,00 & & 0,67 & 0,00 & & \\
\hline & 1/3.h & 1,01 & & & 6,00 & & 0,81 & 0,00 & & \\
\hline \multirow{4}{*}{$26 / 03 / 14$} & Fundo* & 6,93 & & & 4,40 & & 1,08 & 1,50 & & \\
\hline & 3/3.h & 5,98 & 7.18 & 10 & 4,00 & 4.09 & 0,98 & 0,00 & a & 0.57 \\
\hline & $2 / 3 . \mathrm{h}$ & 3,59 & & & 4,00 & & 0,98 & 0,00 & a & \\
\hline & 1/3.h & 1,20 & & & 3,00 & & 0,73 & 0,00 & & \\
\hline & Fundo* & 6,50 & & & 8,00 & & 1,02 & 2,16 & & \\
\hline $15 / 04 / 14$ & 3/3.h & 5,63 & 6.75 & 15 & 7,40 & 7,82 & 0,95 & 0,00 & a & 1,49 \\
\hline & $2 / 3 . \mathrm{h}$ & 3,38 & & 15 & 8,00 & 1,02 & 1,02 & 0,00 & a & 1,49 \\
\hline & 1/3.h & 1,13 & & & 8,40 & & 1,07 & 0,00 & & \\
\hline & Fundo* & 5,95 & & & 6,60 & & 1,27 & 0,70 & & \\
\hline $07 / 05 / 14$ & 3/3.h & 5,17 & 6.20 & 5 & 4,20 & 5,18 & 0,81 & 0,00 & a & 0,40 \\
\hline $07 / 03 / 14$ & $2 / 3 . \mathrm{h}$ & 3,10 & 0,20 & 3 & 4,80 & 5,10 & 0,93 & 0,00 & a & 0,40 \\
\hline & 1/3.h & 1,03 & & & 3,00 & & 0,58 & 0,00 & & \\
\hline & Fundo* & 5,55 & & & 5,00 & & 1,18 & 1,33 & & \\
\hline $22 / 05 / 14$ & 3/3.h & 4,83 & 5,80 & 10 & 3,40 & 4,23 & 0,80 & 0,00 & a & 0,57 \\
\hline $22 / 00114$ & $2 / 3 . \mathrm{h}$ & 2,90 & 5,00 & 10 & 4,00 & 4,25 & 0,95 & 0,00 & a & 0,31 \\
\hline & 1/3.h & 0,97 & & & 4,60 & & 1,09 & 0,00 & & \\
\hline & Fundo* & 5,75 & & & 7,80 & & 1,07 & 1,76 & & \\
\hline $03 / 06 / 14$ & 3/3.h & 5,00 & 600 & 13 & 7,80 & 727 & 1,07 & 0,00 & 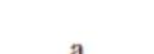 & 10 \\
\hline $03 / 00 / 14$ & $2 / 3 . \mathrm{h}$ & 3,00 & 0,00 & 13 & 4,80 & 7,21 & 0,66 & 0,00 & a & 1,19 \\
\hline & $1 / 3 . \mathrm{h}$ & 1,00 & & & 9,00 & & 1,24 & 0,00 & & \\
\hline & Fundo* & 7,25 & & & 12,60 & & 0,97 & 35,13 & & \\
\hline $09 / 06 / 14$ & 3/3.h & 6,25 & 7.50 & 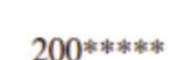 & 11,60 & 12.92 & 0,90 & 0,00 & b & 200,80 \\
\hline $09 / 00 / 14$ & $2 / 3 . \mathrm{h}$ & 3,75 & 1,00 & $200 \times+1$. & 15,00 & 12,92 & 1,16 & 0,00 & 0 & 200,00 \\
\hline & 1/3.h & 1,25 & & & 15,20 & & 1,18 & 123,78 & & \\
\hline & Fundo* & 6,95 & & & 17,00 & & 1,09 & 0,75 & & \\
\hline $16 / 06 / 14$ & 3/3.h & 6,00 & 7,20 & 5 & 15,00 & 15,62 & 0,96 & 0,00 & d & 2,38 \\
\hline $10 / 00 / 14$ & $2 / 3 . \mathrm{h}$ & 3,60 & 1,20 & J & 14,20 & 15,02 & 0,91 & 0,00 & 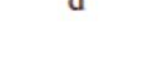 & 2,30 \\
\hline & 1/3.h & 1,20 & & & 15,00 & & 0,96 & 0,99 & & \\
\hline & Fundo & 7,09 & & & 10,40 & & 1,35 & 0,00 & & \\
\hline $09 / 07 / 14$ & 3/3.h & 6,12 & 7,34 & 0 & 5,80 & 7.68 & 0,75 & 0,00 & c & 0.56 \\
\hline $09 / 01 / 14$ & $2 / 3 . \mathrm{h}$ & 3,67 & 7,34 & 0 & 6,00 & 1,08 & 0,78 & 0,00 & c & 0,ग0 \\
\hline & 1/3.h & 1,22 & & & 6,40 & & 0,83 & 1,02 & & \\
\hline
\end{tabular}

* Dados de CSS usados na análise estatística; ** Comporta do descarregador de fundo principal; *** Média ponderada pela carga hidráulica dos pontos de amostragem de CSS $\left(\mathrm{mg} . \mathrm{I}^{-1}\right)$; **** Valor de CSS pontual dividido pela média ponderada das 4 medições. Valor $\geq 1$ destacado em cinza; ****** Descarregador de fundo secundário também foi aberto $(100 \mathrm{~cm})$. 
Tabela 1. Síntese dos dados amostrais (continuação).

\begin{tabular}{|c|c|c|c|c|c|c|c|c|c|c|}
\hline \multirow{2}{*}{ Data } & \multicolumn{2}{|c|}{ Amostra } & \multirow{2}{*}{$\begin{array}{c}\text { Nível } \\
(\mathrm{m})\end{array}$} & \multirow{2}{*}{$\begin{array}{c}\text { Abertura } \\
\text { C.G. }(\mathrm{cm})^{* *}\end{array}$} & \multirow{2}{*}{$\begin{array}{c}\text { CSS } \\
\left(\mathrm{mg} . \mathrm{I}^{-1}\right)\end{array}$} & \multirow{2}{*}{$\begin{array}{l}\text { Média P. } \\
(\mathrm{CSS})^{* * * *}\end{array}$} & \multirow{2}{*}{$\begin{array}{c}\text { Perfil } \\
\text { CSS***** }\end{array}$} & \multirow{2}{*}{$\begin{array}{c}\mathrm{Q} \\
\left(\mathrm{m}^{3} \cdot \mathrm{s}^{-1}\right) \\
\end{array}$} & \multirow{2}{*}{ Operação } & \multirow{2}{*}{$\underset{\left(\text { t.dia }^{-1}\right)}{\text { DS }}$} \\
\hline & Posição & $h(m)$ & & & & & & & & \\
\hline \multirow{4}{*}{$14 / 07 / 14$} & Fundo & 7,07 & \multirow{4}{*}{7,32} & \multirow{4}{*}{0} & 8,60 & \multirow{4}{*}{7,13} & 1,21 & 0,00 & \multirow{4}{*}{ c } & \multirow{4}{*}{0,53} \\
\hline & 3/3.h & 6,10 & & & 6,20 & & 0,87 & 0,00 & & \\
\hline & 2/3.h & 3,66 & & & 6,20 & & 0,87 & 0,00 & & \\
\hline & 1/3.h & 1,22 & & & 6,00 & & 0,84 & 1,02 & & \\
\hline \multirow{4}{*}{$22 / 07 / 14$} & Fundo* & 6,95 & \multirow{4}{*}{7,20} & \multirow{4}{*}{5} & 12,80 & \multirow{4}{*}{10,22} & 1,25 & 0,75 & \multirow{4}{*}{ d } & \multirow{4}{*}{1,62} \\
\hline & 3/3.h & 6,00 & & & 8,40 & & 0,82 & 0,00 & & \\
\hline & 2/3.h & 3,60 & & & 8,60 & & 0,84 & 0,00 & & \\
\hline & 1/3.h & 1,20 & & & 9,20 & & 0,90 & 0,99 & & \\
\hline \multirow{4}{*}{$22 / 08 / 14$} & Fundo* & 6,55 & & & 10,00 & & 1,35 & 0,44 & & \\
\hline & 3/3.h & 5,67 & 6.80 & 3 & 6,80 & 7,40 & 0,92 & 0,00 & d & 0.63 \\
\hline & 2/3.h & 3,40 & 0,80 & 3 & 4,80 & 1,40 & 0,65 & 0,00 & a & 0,03 \\
\hline & 1/3.h & 1,13 & & & 3,20 & & 0,43 & 0,90 & & \\
\hline & Fundo & 6,60 & & & 22,40 & & 1,55 & 0,00 & & \\
\hline $05 / 09 / 14$ & 3/3.h & 5,71 & 6.85 & 0 & 8,80 & 14.46 & 0,61 & 0,00 & $c$ & 080 \\
\hline 0070914 & 2/3.h & 3,43 & & & 10,00 & & 0,69 & 0,00 & $\mathrm{c}$ & 0,00 \\
\hline & 1/3.h & 1,14 & & & 10,20 & & 0,71 & 0,91 & & \\
\hline & Fundo* & 6,53 & & & 10,20 & & 1,35 & 0,44 & & \\
\hline $12 / 09 / 14$ & 3/3.h & 5,65 & 678 & 3 & 6,00 & 753 & 0,80 & 0,00 & d & 0.91 \\
\hline & 2/3.h & 3,39 & 0,10 & & 5,20 & & 0,69 & 0,00 & & 0,91 \\
\hline & 1/3.h & 1,13 & & & 6,80 & & 0,90 & 0,89 & & \\
\hline & Fundo & 6,91 & & & 7,20 & & 1,12 & 0,00 & & \\
\hline $03 / 10 / 14$ & 3/3.h & 5,97 & 7.16 & 0 & 5,60 & 6.46 & 0,87 & 0,00 & c & 0.51 \\
\hline & 2/3.h & 3,58 & & & 6,60 & & 1,02 & 0,00 & & \\
\hline & 1/3.h & 1,19 & & & 6,00 & & 0,93 & 0,98 & & \\
\hline & Fundo* & 6,75 & & & 10,20 & & 1,28 & 1,48 & & \\
\hline $24 / 10 / 14$ & 3/3.h & 5,83 & 7.00 & 10 & 6,80 & 7.98 & 0,85 & 0,00 & d & 1.92 \\
\hline & 2/3.h & 3,50 & & & 5,80 & & 0,73 & 0,00 & & \\
\hline & 1/3.h & 1,17 & & & 7,60 & & 0,95 & 0,95 & & \\
\hline & Fundo* & 6,48 & & & 10,40 & & 1,25 & 1,16 & & \\
\hline $04 / 11 / 14$ & 3/3.h & 5,61 & 6.73 & 8 & 7,60 & 8,30 & 0,92 & 0,00 & d & 1,36 \\
\hline & 2/3.h & 3,37 & & & 6,80 & & 0,82 & 0,00 & & \\
\hline & 1/3.h & 1,12 & & & 4,20 & & 0,51 & 0,88 & & \\
\hline & Fundo & 6,55 & & & 11,60 & & 1,21 & 0,00 & & \\
\hline $05 / 11 / 14$ & 3/3.h & 5,67 & 6.80 & 0 & 9,40 & 9.62 & 0,98 & 0,00 & c & 0,42 \\
\hline $03 / 11 / 14$ & 2/3.h & 3,40 & 0,80 & 0 & 7,60 & 9,02 & 0,79 & 0,00 & c & 0,42 \\
\hline & 1/3.h & 1,13 & & & 5,40 & & 0,56 & 0,90 & & \\
\hline & Fundo & 6,57 & & & 14,40 & & 1,29 & 0,00 & & \\
\hline $06 / 11 / 14$ & 3/3.h & 5,68 & 6,82 & 0 & 9,60 & 11,17 & 0,86 & 0,00 & c & 0,72 \\
\hline $00 / 111 / 14$ & 2/3.h & 3,41 & 0,82 & 0 & 8,20 & 11,17 & 0,73 & 0,00 & c & 0,12 \\
\hline & 1/3.h & 1,14 & & & 9,20 & & 0,82 & 0,90 & & \\
\hline
\end{tabular}

* Dados de CSS usados na análise estatística; ** Comporta do descarregador de fundo principal; *** Média ponderada pela carga hidráulica dos pontos de amostragem de CSS $\left(\mathrm{mg} . \mathrm{I}^{-1}\right)$; **** Valor de CSS pontual dividido pela média ponderada das 4 medições. Valor $\geq 1$ destacado em cinza; ***** Descarregador de fundo secundário também foi aberto $(100 \mathrm{~cm})$.

Tabela 2. Proporção de ocorrência de cada operação da barragem.

\begin{tabular}{cccc}
\hline Operação & $\begin{array}{c}2010 \text { a } 2014 \\
(\%)\end{array}$ & $\begin{array}{c}2014 \\
(\%)\end{array}$ & $\begin{array}{c}\text { Amostra } \\
(\%)\end{array}$ \\
\hline A & 88,56 & 43,29 & 35 \\
B & 0,22 & 0,55 & 5 \\
C & 4,05 & 20,27 & 30 \\
D & 7,17 & 35,89 & 30 \\
\hline
\end{tabular}


Os dados pontuais de CSS medidos nas três camadas d'água e no fundo podem ser visualizados na Figura 7 , onde se observa a tendência para maior concentração de sedimentos suspensos no fundo do reservatório, conforme mostrado na Tabela 1, reduzindo nas demais camadas d'água, estando as 4 medições com valores bastante próximos na maioria das campanhas. Em relação a estratificação das camadas d'água merece destaque a campanha do dia 05/09/2014, onde a amostragem realizada ao fundo do reservatório apresentou um valor duas vezes maior em relação às medições nas camadas d'água superiores, sendo superior também em relação a todas as demais campanhas amostrais, indicando a ocorrência de uma corrente de turbidez de fundo, conforme descrição de Alves (2008). Ao observar a Figura 7 se constata que, o conjunto das 4 amostragens do dia 16/09/2014 possui maior concentração de sedimentos suspensos que o conjunto das 4 amostragens durante o pico de vazão ocorrido no dia 09/06/2014, indicando que o pico da descarga sólida em suspensão exposto na Figura 8 é determinado sobretudo pela vazão, e que o segundo pico é determinado pela CSS.

Como o nível do reservatório é variável, apesar de considerar a mesma quantidade de perfis em todas as amostragens, com exceção da coleta no fundo as demais não se mantiveram exatamente no mesmo ponto, desta forma, visando comparar os perfis de CSS na coluna d'água com maior precisão, considerouse arbitrariamente a medição no fundo do reservatório como cota 0 metros, e a partir daí os pontos de amostragem foram definidos para 1 metro, 3 metros e 5 metros (referenciados ao fundo do reservatório), sendo os valores de CSS interpolados linearmente para estes pontos, com base nos valores medidos. Na Tabela 3 está exposta a proporção média da diferença entre o perfil da coluna d'água com maior CSS para os demais perfis por faixa de vazão (Quartis), onde se constata que para menor faixa de vazão (até o primeiro quartil da vazão de amostragem de CSS) a maior concentração de sedimentos esta no perfil do fundo do reservatório, reduzindo em média de $35,56 \%$ nas camadas superiores. $\mathrm{Na}$ faixa de vazão entre o primeiro e o terceiro quartil, a maior concentração de sedimentos suspensos é predominantemente no perfil do fundo do reservatório (com uma campanha com a maior concentração no perfil superior), reduzindo em média $26,64 \%$ para as camadas superiores. Já na faixa de vazão acima do terceiro quartil da vazão dos dias de amostragem de CSS, a maior concentração de sedimentos suspensos esta na camada superior, e a CSS reduz em média de $10,74 \%$ para as camadas inferiores.

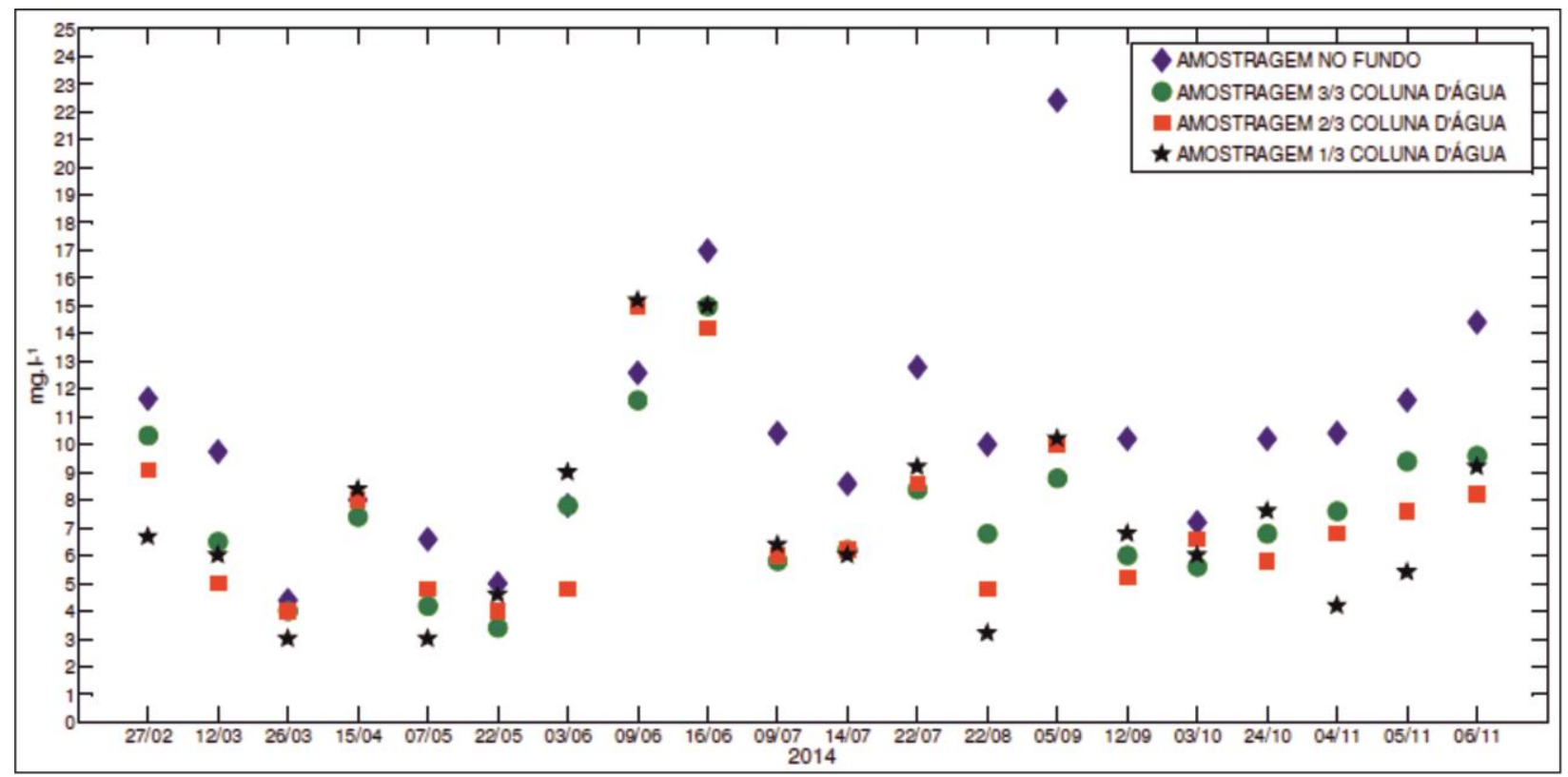

Figura 7. Campanhas de amostragem de CSS, medidas pontuais. 


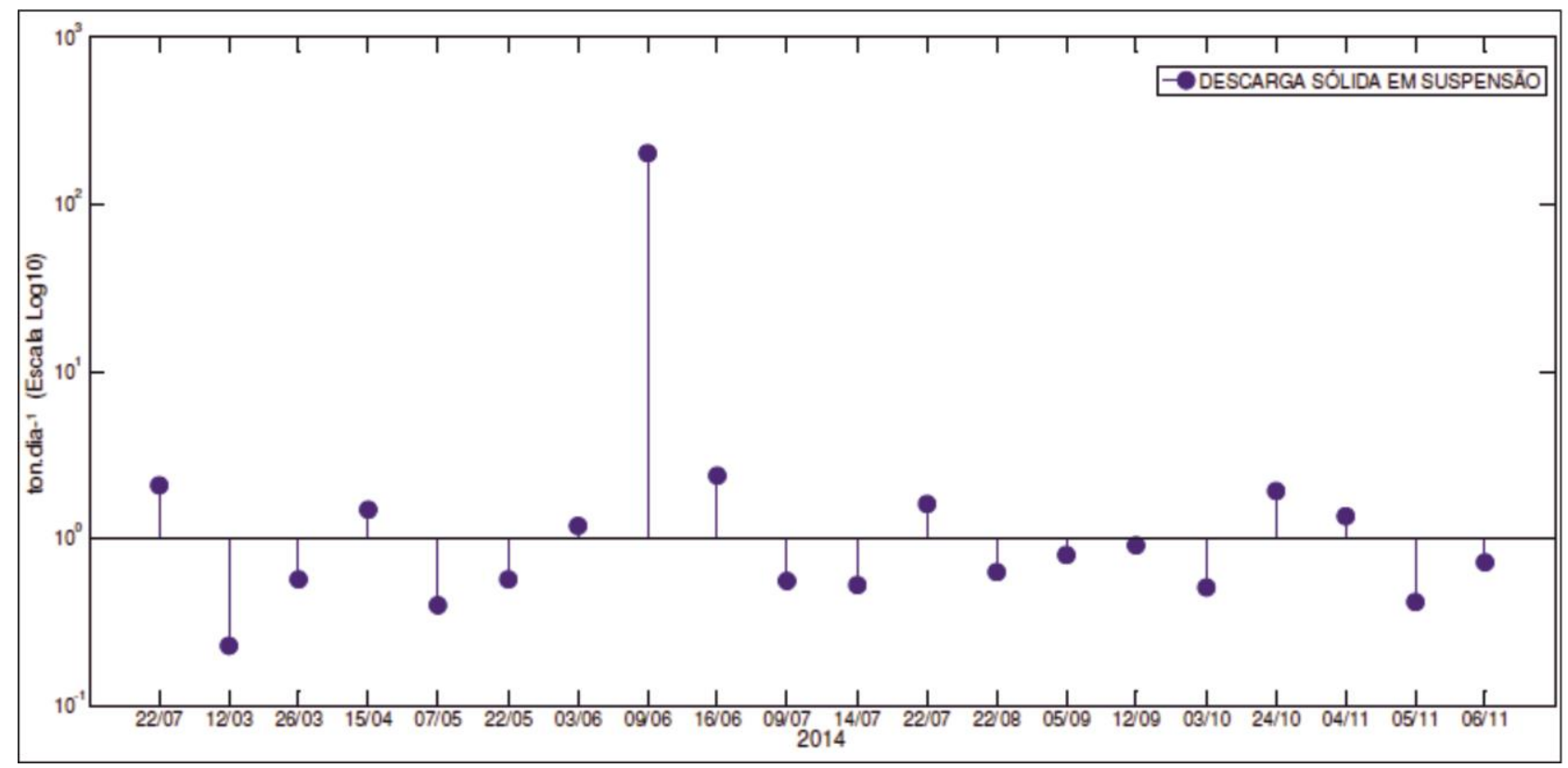

Figura 8. Descarga Sólida da Represa Caunal. Escala Log10.

Tabela 3. Proporção da diferença média em relação ao perfil com maior CSS por faixa de vazão.

\begin{tabular}{|c|c|c|c|}
\hline \multirow{2}{*}{$\begin{array}{c}\text { Perfil Coluna } \\
\text { D'água }\end{array}$} & \multicolumn{3}{|c|}{ Faixa de Vazão (Por Quartis) } \\
\hline & $\leq 1^{\circ} \mathrm{Qt}\left(\leq 1,33 \mathrm{~m}^{3} \cdot \mathrm{s}^{-1}\right)$ & $1^{\circ} \mathrm{Qt}>\leq 3^{\circ} \mathrm{Qt}\left(1,34\right.$ a $\left.2,06 \mathrm{~m}^{3} \cdot \mathrm{s}^{-1}\right)$ & $>3^{\circ} \mathrm{Qt}\left(>2,07 \mathrm{~m}^{3} \cdot \mathrm{s}^{-1}\right)$ \\
\hline Fundo $(0 \mathrm{~m})^{*}$ & Maior CSS & Predominantemente Maior CSS & $10,34 \%$ Menor (Média) \\
\hline $0+1 \mathrm{~m} * *$ & $35,08 \%$ Menor (Média) & $20,78 \%$ Menor (Média) & $17,04 \%$ Menor (Média) \\
\hline $0+3 m^{*} * *$ & $35,58 \%$ Menor (Média) & 29,76 \% Menor (Média) & 4,84 \% Menor (Média) \\
\hline $0+5 \mathrm{~m} * *$ & $36,02 \%$ Menor (Média) & 29,39 \% Menor (Média) & Maior CSS \\
\hline
\end{tabular}

A Figura 9 contempla a superfície 2D dos dados de CSS interpolados. Cada quadrado contém o valor médio entre as profundidades e campanhas de amostragem que o mesmo se situa, onde é possível observar que entre as três camadas constituídas pela interpolação, o período do evento de máxima ocorrido no mês de Junho/2014 possui os maiores valores. Merece destaque também o pico da CSS de fundo ocorrido em 05/09/2014, devido a ocorrência de uma corrente de turbidez de fundo.

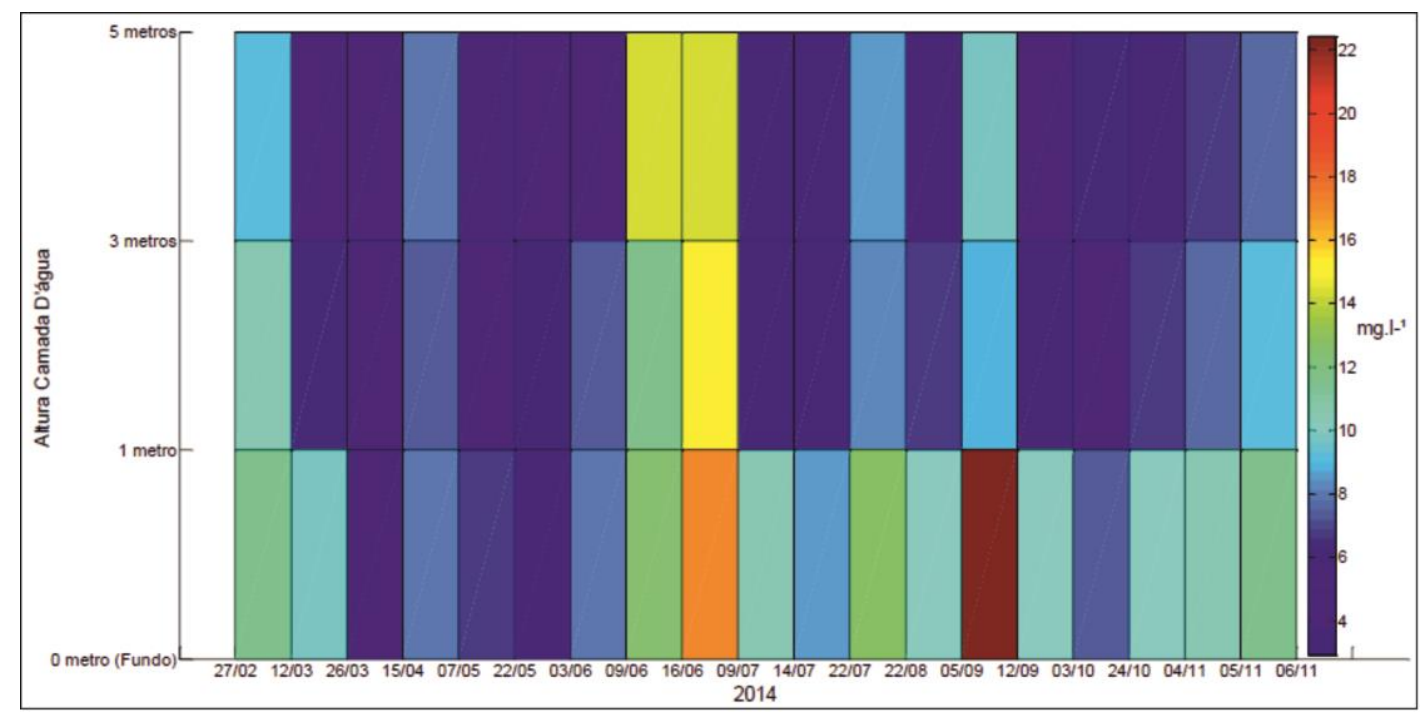

Figura 9. Superfície 2D dos dados de CSS interpolados para as alturas de camada d'água arbitrárias por campanha de amostragem. 
Na Figura 10 é possível observar as campanhas de amostragens sobre o hidrograma e hietograma da represa, onde se verifica que com exceção do evento de máxima, amostrado no dia 09/06/14, todas as demais amostragens se situam em eventos de baixa vazão, havendo a carência de amostragens de eventos intermediários.

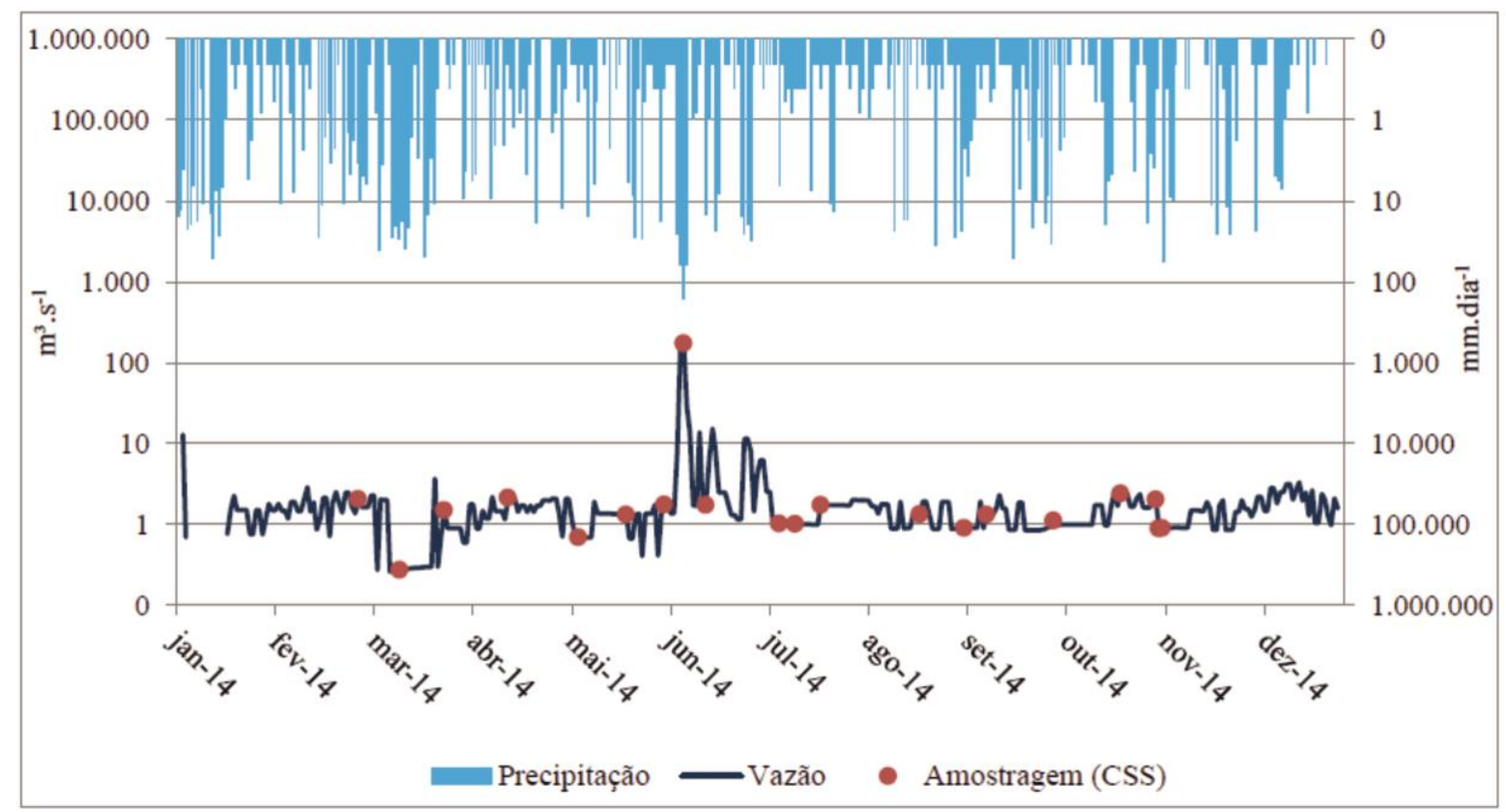

Figura 10. Campanhas de amostragem no hidrograma e hietograma da represa Caunal. Escala de tempo diário.

Vale salientar que a vazão é antropicamente determinada, em função da demanda hídrica na PCH de jusante e do excesso de chuva, e conseqüentemente, a operação da represa amortece os picos dos eventos intermediários e aumenta a vazão nos períodos de mínimas pluviométricas. Na Tabela 4 as médias de CSS ponderadas pela carga hidráulica das 20 campanhas foram agrupadas de acordo com o momento do seu respectivo evento do hidrograma da represa Caunal (ascensão, pico, recessão, vale), evidenciando que 14 campanhas contemplaram o processo de ascensão da vazão e 6 eventos se situaram sobre períodos de recessão da mesma. Tendo como critério a mediana dos 20 dados, se verificou que as maiores concentrações se encontram nos dados do começo de ascensão dos eventos do hidrograma, seguidos, respectivamente pelos dados do pico da ascensão e começo da recessão do mesmo. Já os dados do vale da recessão do hidrograma possuem as menores concentrações, com exceção da amostragem do dia 05/11/2014, realizado após evento pluviométrico.

Tabela 4. Amostragens de CSS nos eventos do hidrograma da represa Caunal.

\begin{tabular}{rrrr}
\hline \multicolumn{2}{c}{ Ascensão } & \multicolumn{2}{c}{ Recessão } \\
\hline Começo & \multicolumn{1}{c}{ Pico } & \multicolumn{1}{c}{ Começo } & Vale \\
\hline 7,43 & 10,35 & 12,92 & 5,18 \\
15,62 & 4,09 & 7,13 & 4,23 \\
7,40 & 7,82 & 8,30 & 9,62 \\
14,46 & 7,27 & & \\
7,53 & 7,68 & & \\
6,46 & 10,22 & & \\
11,17 & 7,98 & \\
\hline d'água) & > Mediana (7,75). \\
\hline Valores destacados: CSS (média ponderada coluna
\end{tabular}


Devido a descarga líquida da represa ocorrer pelo descarregador de fundo em três das quatro formas de operação desta represa, representando $80 \%$ da operação no ano de amostragem e $70 \%$ das campanhas de amostragem de CSS, conforme Tabela 2, sendo que a maior concentração ocorre predominantemente ao fundo do reservatório, conforme Tabela 3, utilizou-se como dado de CSS na análise multivariada somente a CSS do fundo do reservatório nas operações A e D, com sua respectiva vazão.

De acordo com a Tabela 5, a vazão com atraso de 1 e 2 dias apresentou correlação significante com a CSS de 0,37 e 0,45 na correlação de Kendall Tau, respectivamente, e correlação significante de 0,54 e 0,61 na correlação de Spearman Rank, respectivamente. A correlação entre a vazão instantânea e a CSS não foi significante, no entanto, a Tabela 5 mostra que a vazão, apesar de não ser aleatória, possui memória temporal de 3 dias em função da operação da barragem, com nível de confiança de $90 \%$ na correlação de Kendall Tau, sendo que a vazão de lag 2, que alcançou as melhores correlações com a CSS, obteve boa correlação com a vazão de lag 1 (0,51-Kendall Tau / 0,67-Spearman), a qual possui forte correlação com a vazão do dia da amostragem de CSS (0,58-Kendall Tau / 0,71Spearman), todas com nível de confiança de $90 \%$. Outra variável que obteve correlação positiva e com significância com a CSS foi a chuva acumulada entre o lag 1 e lag 2, obtendo o valor de 0,35 na correlação de Kendall Tau.

Como foi encontrada memória temporal nos dados de vazão nas correlações não paramétricas, em função da operação da barragem, foi calculada a correlação serial da vazão através da função autocorrelação parcial (PACF) para o ano de 2014.

Conforme é possível observar na Figura 11, a função autocorrelação parcial decai em dumped sin, havendo memória temporal nos dados até o $\operatorname{lag} 6$, sendo mais expressivo até o lag 3, conforme mostrado nas correlações não paramétricas.

Tabela 5. Correlações Não-Paramétricas (Destacado p com $\alpha$ de 10\%).

\begin{tabular}{|c|c|c|c|c|c|c|c|c|}
\hline \multirow{2}{*}{ Variável } & \multicolumn{8}{|c|}{ KENDALL TAU } \\
\hline & CSS & $\mathrm{p}$ & Q & $\mathrm{p}$ & QLag 1 & $\mathrm{p}$ & QLag 2 & $\mathrm{p}$ \\
\hline CSS & & & 0,21 & 0,32 & 0,37 & 0,07 & 0,45 & 0,03 \\
\hline Q & 0,21 & 0,32 & & & 0,58 & 0,01 & 0,35 & 0,10 \\
\hline QLag 1 & 0,37 & 0,07 & 0,58 & 0,01 & & & 0,51 & 0,01 \\
\hline QLag 2 & 0,45 & 0,03 & 0,35 & 0,10 & 0,51 & 0,01 & & \\
\hline QLag 3 & $-0,09$ & 0,69 & 0,48 & 0,04 & 0,33 & 0,16 & 0,11 & 0,64 \\
\hline QLag 4 & 0,22 & 0,30 & 0,01 & 0,95 & 0,13 & 0,54 & 0,10 & 0,63 \\
\hline P Lag 0 ao Lag 1 & 0,03 & 0,89 & $-0,31$ & 0,14 & $-0,21$ & 0,32 & $-0,01$ & 0,95 \\
\hline P Lag 1 ao Lag 2 & 0,35 & 0,10 & $-0,15$ & 0,47 & $-0,03$ & 0,90 & 0,00 & 1,00 \\
\hline P Lag 2 ao Lag 3 & 0,00 & 1,00 & 0,00 & 1,00 & $-0,01$ & 0,95 & $-0,26$ & 0,22 \\
\hline P Lag 3 ao Lag 4 & 0,04 & 0,84 & $-0,14$ & 0,50 & $-0,11$ & 0,60 & $-0,28$ & 0,18 \\
\hline P Lag 4 ao Lag 5 & 0,20 & 0,34 & 0,47 & 0,03 & 0,40 & 0,06 & 0,11 & 0,61 \\
\hline \multirow{2}{*}{ Variável } & \multicolumn{8}{|c|}{ SPEARMAN RANK } \\
\hline & CSS & $\mathrm{p}$ & Q & $\mathrm{p}$ & QLag 1 & $\mathrm{p}$ & QLag 2 & $\mathrm{p}$ \\
\hline CSS & & & 0,36 & 0,23 & 0,61 & 0,03 & 0,61 & 0,03 \\
\hline Q & 0,36 & 0,23 & & & 0,71 & 0,01 & 0,46 & 0,11 \\
\hline QLag 1 & 0,54 & 0,06 & 0,71 & 0,01 & & & 0,67 & 0,01 \\
\hline QLag 2 & 0,61 & 0,03 & 0,46 & 0,11 & 0,67 & 0,01 & & \\
\hline QLag 3 & $-0,17$ & 0,62 & 0,65 & 0,03 & 0,43 & 0,19 & 0,10 & 0,77 \\
\hline QLag 4 & 0,23 & 0,44 & 0,02 & 0,95 & 0,10 & 0,75 & 0,07 & 0,82 \\
\hline P Lag 0 ao Lag 1 & 0,02 & 0,94 & $-0,39$ & 0,19 & $-0,29$ & 0,33 & $-0,05$ & 0,88 \\
\hline P Lag 1 ao Lag 2 & 0,43 & 0,14 & $-0,16$ & 0,60 & $-0,04$ & 0,91 & $-0,04$ & 0,88 \\
\hline P Lag 2 ao Lag 3 & 0,04 & 0,91 & 0,02 & 0,94 & $-0,06$ & 0,85 & $-0,34$ & 0,26 \\
\hline P Lag 3 ao Lag 4 & 0,06 & 0,85 & $-0,25$ & 0,41 & $-0,14$ & 0,66 & $-0,30$ & 0,32 \\
\hline P Lag 4 ao Lag 5 & 0,33 & 0,28 & 0,64 & 0,02 & 0,51 & 0,07 & 0,14 & 0,64 \\
\hline
\end{tabular}

CSS: concentração de sedimentos em suspensão; Q: vazão; P: chuva acumulada em $24 \mathrm{~h}$. 


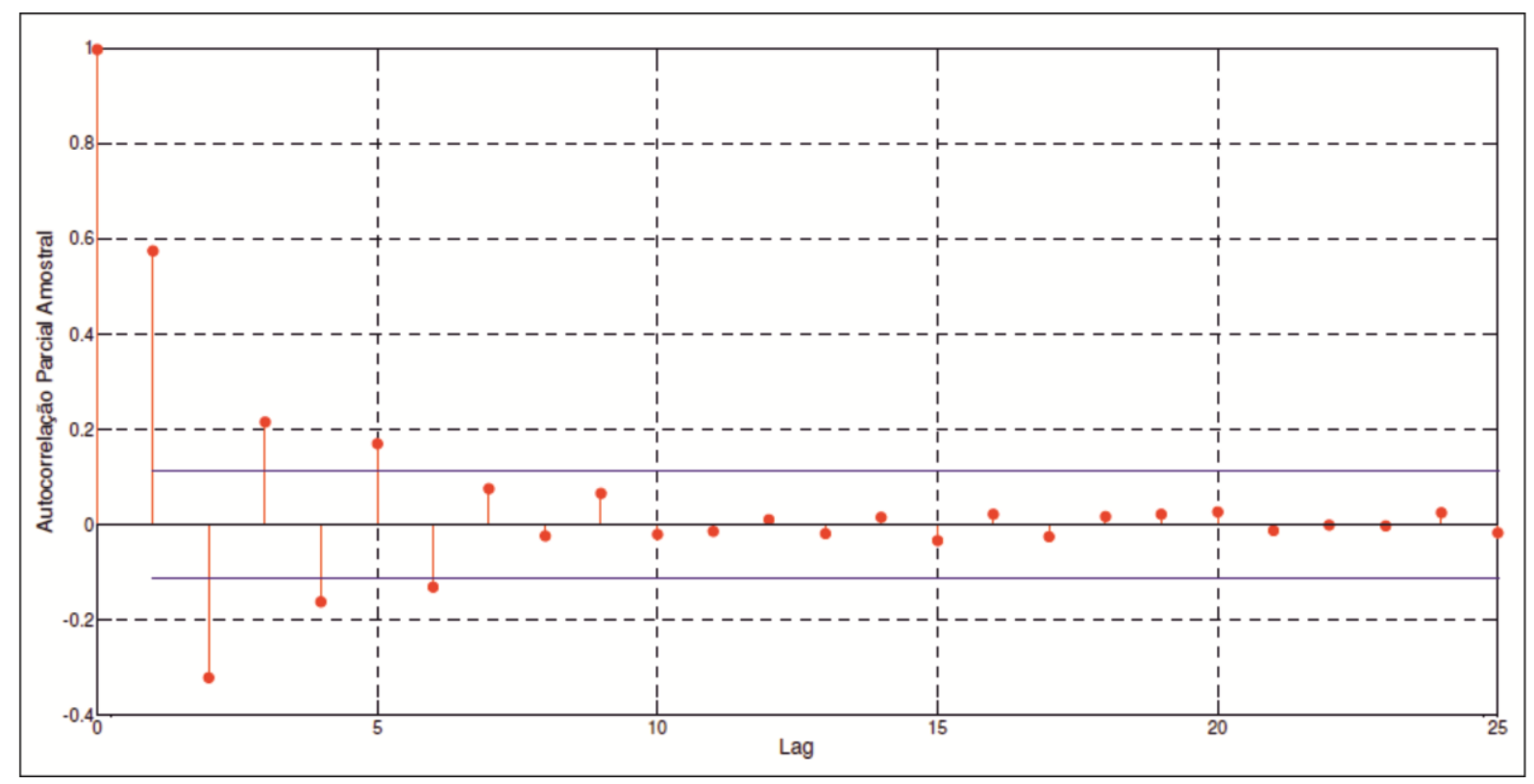

Figura 11. Função Autocorrelação Parcial Amostral da vazão em 2014. Em azul erro padrão.

Para verificar a existência de relações lineares entre as variáveis em análise, foram verificadas se as distribuições de probabilidade, das variáveis que alcançaram correlação com significância $\leq 10 \%$ com a CSS nas correlações não-paramétricas mais a vazão instantânea, são gaussianas. De acordo com a Tabela 6, que apresenta o teste de verificação de nãonormalidade de Shapiro-Wilk, observa-se que a distribuição dos dados de CSS, vazão instantânea e vazão de $\operatorname{lag} 1$ são normais, enquanto as variáveis vazão de lag 2 e chuva acumulada em $24 \mathrm{~h}$ entre os lags 1 e 2, não possuem normalidade em suas distribuições de probabilidade, necessitando ser transformadas.

Através da verificação do valor de lambda $(\lambda)$, foram obtidos valores próximos de zero e com o intervalo de confiança de $95 \%$ englobando o zero absoluto, conforme Tabela 7, desta forma foi realizada a transformação logarítmica de base 10 para normalizar estas variáveis.

Tabela 6. Teste de Shapiro-Wilk. Destacado testes não validados $\mathrm{p} / \alpha$ de 5\% (Gaussianas).

\begin{tabular}{ccc}
\hline Variável & Shapiro-Wilk & $\alpha$ \\
\hline CSS & 0,95 & 0,61 \\
Q Instantânea & 0,94 & 0,41 \\
Q Lag 1 & 0,98 & 0,98 \\
Q Lag 2 & 0,48 & 0,00 \\
PLag 1 ao Lag 2 & 0,48 & 0,00 \\
\hline
\end{tabular}

CSS: concentração de sedimentos em suspensão; $Q$ : vazão; P: chuva.

Tabela 7. Valores de Lambda $(\lambda)$ para as variáveis sem normalidade.

\begin{tabular}{cccc}
\hline \multirow{2}{*}{ Variável } & $\lambda$ & \multicolumn{2}{c}{ IC } \\
\cline { 3 - 4 } & & $<95 \%$ & $>95 \%$ \\
\hline Q Lag 2 & $-0,23$ & $-0,79$ & 0,24 \\
PLag1 ao Lag 2 & $-0,33$ & $-0,74$ & 0,01 \\
\hline Q: vazão; P: chuva; IC: intervalo de confiança.
\end{tabular}

Com a transformação logarítmica de base 10 foi possível normalizar a distribuição da vazão de $\operatorname{lag} 2$, conforme Tabela 8, no entanto a chuva acumulada em $24 \mathrm{~h}$ entre os lags 1 e 2, conforme a mesma Tabela citada anteriormente, não alcançou a normalidade de 
acordo com o teste de Shapiro-Wilk, mas a distribuição de seus dados ficou mais próxima de uma gaussiana do que os dados originais, e desta forma considerou-se esta variável transformada para as análises paramétricas.

Tabela 8. Teste de Shapiro-Wilk. Destacado testes não validados $\mathrm{p} / \alpha$ de 5\% (Gaussianas).

\begin{tabular}{ccc}
\hline Variável & Shapiro-Wilk & $\mathrm{p}$ \\
\hline Log10 - Q Lag 2 & 0,88 & 0,08 \\
Log10 - PLag 1 ao Lag 2 & 0,84 & 0,02 \\
\hline \multicolumn{2}{c}{ Q: vazão; P: chuva. }
\end{tabular}

Com variáveis de distribuição gaussiana, ou bastante próximas da normalidade, foi calculada a correlação linear de Pearson-r, considerando válidas as correlações com significância de 5\% para construir o modelo de regressão linear. Conforme é possível observar na Tabela 9, somente a vazão de $\operatorname{lag} 2$ e a chuva acumulada em $24 \mathrm{~h}$ entre os lags 1 e 2 possuem correlação linear significante com a CSS. A relação linear entre a vazão de lag 2 com a vazão de $\operatorname{lag} 1$, e desta com a vazão instantânea, também esteve presente sob nível de confiança de $95 \%$.

Com o logaritmo de base 10 da vazão de lag 2 e da chuva acumulada em $24 \mathrm{~h}$ entre os lags 1 e 2 foi construído o modelo de regressão linear multivariado. Primeiramente foram calculados os valores de F-Fisher para adicionar e remover variáveis, e calculados os coeficientes de regressão, caso as variáveis sejam aceitas pelo modelo, de acordo com os valores de entrada e saída de F-Fisher, resultando na equação 9.

$$
\begin{array}{r}
C S S_{\text {fundo }}=9,24+5,09 \log _{10} \operatorname{Vazão}_{\operatorname{Lag} 2} \\
+1,94 \log _{10} \text { Chuva }_{\operatorname{Lag} 1 \text { ao Lag } 2} \\
\text { Equação } 9
\end{array}
$$

De acordo com as Tabelas 10 e 11 os coeficientes de regressão e a intercepta foram validados pelo teste de t-student e pela ANOVA. Segundo o coeficiente de determinação ajustado pelos graus de liberdade $\left(\mathrm{R}^{2} \mathrm{p}\right)$ o modelo explica o comportamento de 64\% dos dados de CSS do fundo da represa Caunal, com um erro de estimativa de 2,01 mg. $1^{-1}$. Os resíduos deste modelo apresentaram distribuição normal (Significância de ShapiroWilk com valor de $\mathrm{p}=0,64$ ), não havendo linearidade destes com as variáveis preditoras

\begin{tabular}{|c|c|c|c|c|c|c|c|c|}
\hline \multicolumn{9}{|c|}{ PEARSON-R } \\
\hline Variável & CSS & $\mathrm{p}$ & Q & $\mathrm{p}$ & QLag 1 & $\mathrm{p}$ & $\log 10$ - QLag 2 & $\mathrm{p}$ \\
\hline CSS & & & 0,26 & 0,39 & 0,38 & 0,20 & 0,69 & 0,01 \\
\hline Q & 0,26 & 0,39 & & & 0,77 & 0,00 & 0,42 & 0,15 \\
\hline QLag 1 & 0,38 & 0,20 & 0,77 & 0,00 & & & 0,63 & 0,02 \\
\hline $\log 10$ - QLag 2 & 0,69 & 0,01 & 0,42 & 0,15 & 0,63 & 0,02 & & \\
\hline $\log 10-P \operatorname{Lag} 1$ ao $\operatorname{Lag} 2$ & 0,58 & 0,04 & $-0,35$ & 0,24 & $-0,20$ & 0,51 & 0,17 & 0,58 \\
\hline
\end{tabular}
do modelo.

Tabela 9. Correlação Paramétrica. Destacado p com $\alpha$ de $5 \%$.

Tabela 10. Modelo de Regressão Linear Multivariado.

\begin{tabular}{cccccc}
\hline & $\mathrm{B}$ & Erro Padrão B & $\mathrm{t}(10)$ & $\mathrm{p}$ & $\mathrm{n}$ \\
\hline Intercepta & 9,24 & 0,62 & 14,78 & 0,00 & \\
Log10 - QLag 2 & 5,09 & 1,46 & 3,48 & 0,01 & 13 \\
Log10 - P Lag 1 ao Lag 2 & 1,94 & 0,72 & 2,70 & 0,02 & 13 \\
\hline
\end{tabular}

Q: vazão; P: chuva. 
Tabela 11. Estatísticas do Modelo de Regressão Linear Multivariado.

\begin{tabular}{cc}
\hline Parâmetro & Valor \\
\hline F-Int & 0,11 \\
F-Out & 0,05 \\
R $^{2}$ & 0,70 \\
R $^{2} \mathrm{p}$ & 0,64 \\
ANOVA (F) & 11,60 \\
p (ANOVA) & 0,00 \\
Erro Padrão Estimativa & 2,01 \\
\hline
\end{tabular}

\section{CONCLUSÕES}

O amostrador ZN-2014, e o método de amostragem pontual em 4 camadas da coluna d'água, se mostraram eficientes no monitoramento de sedimentos suspensos no exutório da bacia hidrográfica da Represa Caunal.

Com estas amostragens foram identificados diferentes perfis da CSS ao longo da coluna d'água, em função da operação da barragem, e a ocorrência de correntes de turbidez de fundo no reservatório desta represa.

De acordo com as correlações analisadas e com o modelo de regressão linear multivariado validado estatisticamente, constata-se que dois processos hidrossedimentológicos explicam o comportamento de $64 \%$ da concentração de sedimentos suspensos na camada d'água inferior do reservatório em estudo.

Um dos processos é a chuva acumulada em $24 \mathrm{~h}$ entre os lags 1 e 2, a qual constitui uma das entradas de energia para o processo de erosão decorrente na bacia de contribuição da represa $(r=0,58$ sob $\alpha$ de 5\%). Em conseqüência do tempo de concentração desta bacia $(9,36 h)$, esta chuva resultará em um incremento na vazão de lag 1 e, conseqüentemente, incremento de sedimentos suspensos também, pois a correlação de Spearman Rank entre CSS e vazão de lag 1 foi de 0,54 e a correlação de Kendall Tau foi de 0,37 (ambas sob nível de confiança de 90\%).

Como a vazão, que constitui a energia e o ambiente do transporte de sedimentos suspensos, mantém memória nos dados por 2 dias de acordo com as correlações analisadas, principalmente na vazão de lag 1 com a vazão do dia da amostragem de CSS $(r=0,77$ sob $\alpha$ de 5\%), e de até 6 dias de acordo com a função autocorrelação parcial amostral, associado com o tamanho e forma do reservatório (volume de $4,63 \times 10^{7} \mathrm{~m}^{3}$ e comprimento axial de aprox. 9 $\mathrm{km})$, suas características hidrodinâmicas (remanso hidráulico/reduzida velocidade de escoamento), e operação antrópica da barragem (armazenamento hídrico para a demanda da $\mathrm{PCH}$ de jusante), conclui-se que existe um retardo de 2 dias entre o início do processo hidrossedimentológico na bacia de contribuição da represa Caunal, desencadeado pela chuva acumulada em $24 \mathrm{~h}$ entre os lags 1 e 2, e parte da descarga de sedimentos suspensos nesta barragem.

Já o outro processo, referente a vazão de lag 2, que possui a melhor correlação linear com a CSS $(r=0,69$ sob $\alpha$ de $5 \%)$ e maior peso no modelo de regressão, não possui correlação com a chuva acumulada em $24 \mathrm{~h}$ entre os lags 1 e 2, pois cronologicamente não pode receber o aporte hídrico e de sedimentos desencadeado por esta precipitação. Desta forma, estes dados não permitem explicar a gênese deste processo, o qual pode ser fruto do fenômeno de histerese.

No entanto, a memória temporal dos dados de vazão em função da operação da barragem, encontrada nas correlações e PACF, mostram que as características desta vazão possui forte influência sobre as características da vazão do dia de amostragem de CSS, e com isso pode-se confirmar sua determinação na maior parte do comportamento da CSS na descarga da represa Caunal.

Em trabalhos futuros, recomenda-se que seja aumentado o monitoramento espaço/temporal da precipitação, vazão e sedimentos supensos, visando caracterizar de forma mais precisa o processo hidrossedimentológico da vazão de lag 2. Além disso, o monitoramento do transporte de 
sedimentos à montante do reservatório sedimentos em virtude da barragem. possibilitaria quantificar a deposição de

\section{AGRADECIMENTOS}

O primeiro autor gostaria de agradecer a Companhia Volta Grande de Papel - CVG, pelo apoio na realização dos trabalhos de campo, ao bolsista de iniciação científica Felipe Fishmann pela ajuda na elaboração do desenho técnico da barragem, ao CNPq e ao PPGEA/UFSC pela bolsa de mestrado, e à FINEP pelo financiamento da pesquisa.

\section{REFERÊNCIAS BIBLIOGRÁFICAS}

1. ALVES, E.C.T.L. Sedimentação em albufeiras por correntes de turbidez. Lisboa-PT, 2008. Tese (Doutorado em Engenharia Civil) - Laboratório Nacional de Engenharia Civil, Universidade de Lisboa.

2. BORBAS, M.P.\& SEMMELMANN, F.R. Elementos de Engenharia de Sedimentos. In: TUCCI, C.E.M. Hidrologia: Ciência e Aplicação. $2^{\mathrm{a}}$ Ed. Porto Alegre: Ed. UFRGS, 2000.

3. BRANDT, S.A. Classification of geomorphological effects downstream of dams. CATENA. p. 375-401, 2000.

4. CARVALHO,N.O. Hidrossedimentologia Prática. Rio de Janeiro: Interciência, 2008.

5. CLESCERI, L.S., GREENBERG, A.E., EATON, A.D. Standard Methods for the Examination of Water and Wastewater, 20th Edition. APHA American Public Health Association, 1998.

6. COIADO, E.M. Assoreamento de Reservatórios. In: PAIVA, J.B.D. PAIVA, E.M.C.D. (Org.) Hidrologia aplicada a gestão de pequenas bacias hidrográficas. Porto Alegre: ABRH, 2003.

7. FERREIRA, D.C. Estudo do Assoreamento em Albufeiras. Aveiro-PT, 2010. Dissertação (Mestrado em Engenharia Civil) - Departamento de Engenharia Civil, Universidade de Aveiro.

8. INFANTI JR. N. \& FORNASARI FILHO, N. Processos de Dinâmica Superficial. In: OLIVEIRA, A.M.S. BRITO, S.N.A. (Editores) Geologia de Engenharia. São Paulo: Associação Brasileira de Geologia de Engenharia, 1998. 9. HUDSON-HEDWARDS, K. Fluvial Environments. In: PERRY, C. TAYLOR, K. (Edited) Environmental Sedimentology. Ed. Blackwel Publishing, USA, 2007.

10. LINO, J.F.L. Análise da dinâmica hidrossedimentológica da bacia hidrográfica do Rio Preto (SC) com o modelo SWAT. Florianópolis-SC, 2009.
Dissertação (Mestrado em Engenharia Ambiental) Departamento de Engenharia Sanitária e Ambiental, Universidade Federal de Santa Catarina.

11. PORTO, R.M. Hidráulica Básica. 2a Edição. São Carlos: EESC-USP, 2003.

12. SANTOS CORREIA, M.A.A.C. Escoamento de Correntes de Turbidez sob Múltiplos Obstáculos. LisboaPT, 2012. Dissertação (Mestrado em Engenharia Civil) - , Faculdade de Ciências e Tecnologia, Universidade Nova de Lisboa.

13. SINNIGER, R.O. \& HAGER, W.H. Constructions Hydrauliques - Ecoulement Stationnairies. Presses Polytechniques Romandes, Lausanne, 1989.

14. SDS/SC. Secretaria de Desenvolvimento Sustentável de Santa Catarina. Restituição aerofotogramétrica do Estado de Santa Catarina, 2010.

15. SIMÕES, S.J.C. \& COIADO, E.M. Processos Erosivos. In: PAIVA, J.B.D. \& PAIVA, E.M.C.D. (Org.) Hidrologia aplicada a gestão de pequenas bacias hidrográficas. Porto Alegre: ABRH, 2003.

16. YANG, C. T., SIMÕES, F. J. M. Sedimentation Modeling for Rivers and Reservoirs. In: Erosion and Sedimentation Manual. U. S. Department of the Interior Bureau of Reclamation, p. 34-59, 2006.

17. WEY, W.S. Time Series Analysis: Univariate e multivariate methods. Addison Wesley. $2^{\circ}$ Edition. 2006.

18. WILKS, D.S. Statistical methods in the atmospheric sciences. Elsevier. $2^{\circ}$ Edition. 2006.

Manuscrito recebido em: 07 de Novembro de 2016 Revisado e Aceito em: 17 de Fevereiro de 2017 